\title{
Mechanism of fracture of aluminum blanks subjected to stretching along the sheared edge
}

\author{
Nan. Wang, Sergey F. Golovashchenko \\ Oakland University, Rochester, MI 48309, United States \\ nwang@oakland.edu
}

\begin{abstract}
The objective of this study was to investigate the mechanisms of fracture of aluminum blanks subjected to shearing and stretching along the sheared edge. In this study, a new imaging technique was implemented to track the stretching of the sheared edge until fracture. A $1 \mathrm{~mm}$ square grid was etched onto the sheared samples and a video of the sheared surface was taken incrementally during tensile test of the sample.

The influence of cutting clearance in the trimming operation on sheared edge stretchability and mechanism of fracture of sheared surface during its stretching were investigated. Excessive plastic deformation of the burr area during the trimming operation was identified as a major factor leading to early fracture initiation from the tip of the burr. Deburring or solution heat treatment of samples trimmed with excessive clearance may increase stretchability to the level observed for the samples trimmed with accurate alignment of the tools. Roughening of the sheared surface produced with $5 \%$ cutting clearance did not have any significant effect on elongation of the sheared edge.
\end{abstract}

Trimming process with scarp support eliminated burrs on the sheared edge for a large range of cutting clearances and substantially improved sheared edge stretchability.

Keywords: Fracture mechanism, Sheared edge stretchability, Aluminum alloy, Trimming process with scrap support.

\section{Introduction}


One of the difficult manufacturing problems occurring in stamping operations of automotive panels using both aluminum alloys and advanced high strength steels (AHSS) is splitting from the sheared edge when stretching is applied along this surface. A variety of previous studies, concentrated on improving sheared edge quality, often recommended tightening the clearance between the shearing edges. However, smaller clearances (below 6\% of the material thickness) can be problematic for large automotive panels due to high cost of the trimming dies.

In order to successfully resolve the issue of limited stretchability of the sheared edge, it is necessary to understand the mechanisms of fracture. Determining the stretchability that can be anticipated across various cutting conditions can provide helpful recommendations to die designers. Discussion of measures which can be taken if splits are occurring in production conditions is also important.

\section{Literature review}

In previous publications, substantial attention was paid to the quality of sheared edge in order to define the clearance between the cutting edges in blanking, trimming, and piercing operations. Johnson and Slater (1967) investigated the effect of the punch-die radial clearance on the sheared edge finish obtained in different experimental conditions: a series of punches with different diameters and punch-die radial clearances was utilized to study their effect on sheared surface quality. It was concluded that the level of plastic deformation increases, as the radial clearance decreases, and less burring was encountered with the smallest punch-die clearances for bright mild steel, black mild steel, and aluminum.

Multiple attempts were made to analyze the effect cutting clearance has on the shape of the sheared surface. Taupin et al. (1996) analyzed the formation of sheared surface in axisymmetric blanking operation using a rigid plastic finite element model. Golovashchenko et al. (1999) analyzed the effect of clearance on formation of burrs during trimming of aluminum blanks using elasto-plastic FEM model in plane strain formulation and compared the analytical and experimental results for various cutting conditions. 
The effect of cutting angle and the clearance between the shearing edges on formation of burrs was studied by Li (2000). The experimental results indicated that a cutting angle of 20 degrees, a cutting clearance of $5 \%$, and a dull upper shearing edge may eliminate burrs. However, in stamping practice usually all sides of the part require a trimming operation, and the cutting angle is often dictated by the geometry of the part; therefore, arranging a specific cutting angle from all sides is problematic in addition to the difficulty of maintaining a rather consistent cutting clearance. Experimental results provided by Li (2000) indicated that the burr height is very sensitive to cutting parameters and can increase substantially up to $0.3 \mathrm{~mm}$ or even higher for $1 \mathrm{~mm}$ thick sheet if a deviation from optimal cutting conditions occurs.

Mechanisms of the generation of burrs and slivers in conventional trimming were investigated by Golovashchenko (2006). From numerical analysis, bending of scrap was defined as a major reason for burr generation. The results also confirmed that the formation of a small "tongue" on the scrap due to the original crack initiation from the area where material comes out of contact with the upper shearing edge. To eliminate bending of the scrap in trimming, an elastic scarp support was introduced. A small radius of the upper trimming edge was also utilized to prevent separation of slivers from top of the scrap.

An initial study of sheared edge stretchability for aluminum alloy 6111 was published by Golovashchenko (2008). It indicated that burrs are the major source of early fracture when stretching is applied along the sheared edge. The failure mode 1 and failure mode 2 occurring during stretching of sheared edge were discussed in this study.

Stanton et al. (2011) conducted an experimental study of sheared edge stretchability employing the hole expansion test (HET) with both a conical punch and a flat punch for three 5xxx alloys and nine 6xxx alloys for optimal cutting clearance. The effect of variation of the hole punching process parameters occurring in real production processes was not analyzed.

A very detailed experimental analysis of sheared edge stretchability was conducted for 6111-T4 aluminum alloy by Le et al. (2013). Multiple cutting clearances varying from $5 \%$ to $40 \%$, three in-plane orientations: (longitudinal (LD), 
transverse (TD) and diagonal (DD)), several prestrain levels, and cutting angles were tested. However, the fracture initiation mechanism and the fundamental reasons leading to significantly lower elongations were not analyzed.

A number of experimental studies have been performed on stretchability of AHSS using hole expansion ratio (HER) parameter. Chintamani and Sriram (2006) performed the hole expansion test for DP500, BH210 and DQSK steels with variation of die radial clearances ranging from $5 \%$ to $55 \%$ of the material thickness. The general trend was that HER slightly increased with the growth of the clearance from $5 \%$ to $10-15 \%$ clearance and then decreased (by approximately a factor of $2.5-3)$ with the cutting clearance of $55 \%$.

In the experimental study reported by Konieczny and Henderson (2007), sheared surface parameters and HER were studied for HSLA 340, DP590, TRIP780, DP780 and DP980 steels for cutting clearances in the range between $1.1 \%$ and $20 \%$. The effect of cutting clearance on HER ratio varied from one material to another and differed significantly from the results reported by Chintamani and Sriram (2006). HER ratio was stable in the whole range of clearances (HSLA340), stable and then increasing (DP780, TRIP780 and DP980), or decreasing and then increasing (DP590).

Chiriac (2010) studied the behavior of DP780 steel during incremental HET by analyzing the evolution of the major strains along the sheared edge. The results of HER using different punches indicated that performance of the sheared edges in stretching is extremely dependent on tooling configurations.

More recently, Pathak et al. (2014) compared the HER results for reamed and pierced holes with $12 \%$ punch clearance for hot-rolled multi-phase steels as well as for DP600 and DP780 sheets. As in previous studies, it was confirmed that substantially lower HER can be achieved for pierced holes which confirms the conclusions of prior publications investigating similar materials. Numerical results on hole expansion of reamed and punched holes were presented by Butcher et al. (2013) based on a simplifying assumption that sheared surface is formed as a simple shear process with constant triaxiality through the thickness of the blank.

It should be admitted that the results on stretchability of the sheared edge fabricated by piercing of $10 \mathrm{~mm}$ round holes according to International Standard 
ISO16630-2009 "Metallic materials - Sheet and strip - Hole expanding test" are more applicable to cases when the dimensions of the pierced hole or blanked workpiece are relatively small. In this case very accurate control of cutting clearance and very sharp cutting edges are possible. However, in trimming of stamped panels produced in automotive industry, accurate alignment of cutting edges along the perimeter of the panel which might be several meters long is very problematic. Therefore, a broader range of clearances needs to be taken into account to characterize stretchability of sheared edges. Moreover, cutting conditions for piercing of a $10 \mathrm{~mm}$ round hole employed in the hole expansion test are substantially different from the cutting conditions in trimming of a wide flange: the burr height in trimming operation is substantially larger than in the hole piercing process for identical clearances which can be illustrated by comparing of $1.5 \%$ of sheet thickness burr heights in hole piercing experiment of DP600 sheet by Konieczny and Henderson (2007) and 25\% of $t$ burr height reported for very similar material DP600 and die clearance in strip trimming conditions by Golovashchenko and Ilinich (2005). This can be explained by the large bending angle of the scrap in trimming and fairly rigid behavior of the scrap in piercing of a small hole.

The objective of this research is to study sheared edge stretchability, understand the reasons leading to early fracture from sheared edge and develop potential solutions to improve stretchability of trimmed parts.

\section{Experimental procedure for trimming and sheared edge stretchability analysis}

Schematic of conventional trimming process employed in this study is shown in Fig. 1: the tested sample was clamped by the clamping pad and the lower trim steel. The upper trim steel moved downwards to cut the sample. 


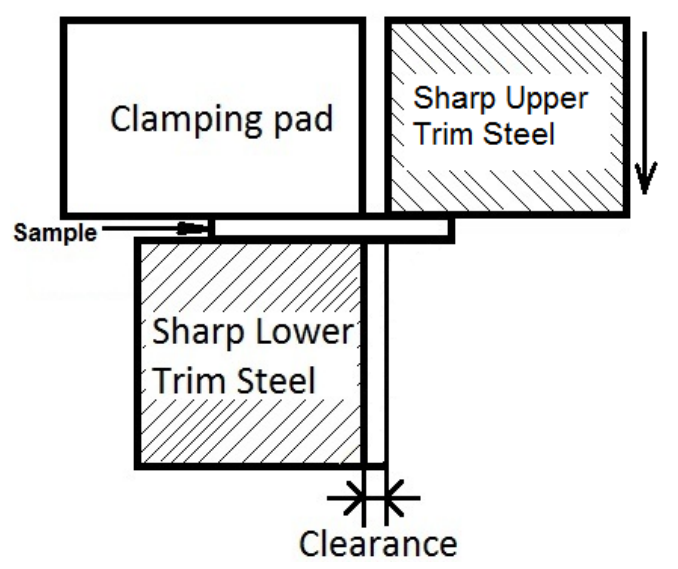

Figure. 1 The schematic of conventional trimming

The specimen geometry was based on the tensile testing ASTM E8 Standard and multiple prior experimental studies. In order to vary trimming conditions in one tool, one side of the sample was made straight while the other side had a half dog-bone shape. This sample design and the procedure of sample fabrication using a dedicated blanking die was previously discussed in details by Le et al. (2013).

The experimental trimming die employed in this study was fabricated in a die shoe to provide sufficient tool stiffness against opening of the clearance between the shearing edges due to significant cutting forces and to achieve necessary tooling alignment accuracy. A microscope was used to measure the radii of the trimming tools and the radii of imprints of sheared edges at the initial stage of trimming. Both measurements led to approximately $0.01 \mathrm{~mm}$ radii of both upper and lower tools employed in conventional trimming.

The aluminum sheet $6111-\mathrm{T} 4$ was $0.9 \mathrm{~mm}$ thick and had the following properties: yield stress of $144 \mathrm{MPa}$; tensile stress of $264 \mathrm{MPa}$; total elongation of $26 \%$, n-value 0.28 ; and plastic strain ratios: $\mathrm{r} 0=0.65, \mathrm{r} 45=0.6, \mathrm{r} 90=0.55$.

The experimental methodology was based on the following testing sequence: (1) half dog-bone samples were blanked out of flat sheet; (2) blanked samples were trimmed in such a way that half dog-bone side was parallel to the trimmed side by employing special locating pins in the trim tool; (3) trimmed half dog-bone samples were carefully metal finished on the half dog-bone side and subsequently electro-etched on one side to obtain $2 \mathrm{~mm}$ diameter circle grids for measuring local strains; (4) tensile tests of the gridded samples were performed employing an 
extensometer with a $50.8 \mathrm{~mm}$ gauge length; (5) measurements of local strains were performed with an automated circle grid analyzer (CGA); (6) cross sections of trimmed half dog-bone samples were mounted in a cylindrical block and filled with epoxy. Then, they were ground, polished, etched and photographed to create metallographic pictures of the cross section of the trimmed samples. Obtained cross-sections were examined in order to understand the effect of trimming parameters on formation of sheared surface.

Measurement of sheared edge stretchability of aluminum alloy was conducted based on methodology described in the paper by Le et al. (2013). For each sample, the measurement was dependent on the location of the fracture, both cases are shown in Fig.2. Measurements were taken in close proximity to the trim line. If the crack propagates through one ellipse (case 1), the major strain in the fractured ellipse, designated Type I, two adjacent ellipses, marked as Type III, and one remote ellipse, Type IV, located approximately $15 \mathrm{~mm}$ from the fractured ellipse were measured. If the crack instead propagates between two ellipses (case 2), both ellipses, designated Type II, were measured as well as one Type IV ellipse located approximately $15 \mathrm{~mm}$ from the fracture were measured. In both cases, the extensometer measurement of total elongation was recorded.

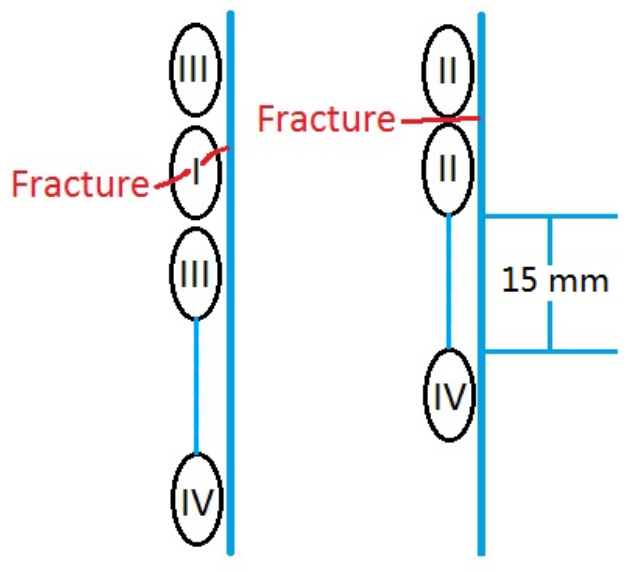

Case 1

Case 2

Figure. 2 Measurement of ellipses defining the fracture strain in the vicinity of the trim line during sheared edge stretching test

Type I and larger Type II strains were designated to the fractured or localized category. Type III and Type IV strains were considered safe. With this 
filtering approach, fractured or localized measurements should always be above the forming limit curve, and all safe measurements should be below this line.

\section{Methodology of fracture initiation study during stretchability experiments}

An attempt was made in this study to identify specific features on the sheared surface which could lead to its fracture during the tensile test. In order to accomplish this, a coordinate system should be established on the sheared surface, and monitoring of the sheared surface transformation during the tensile test should be conducted.

A digital camera system was employed to record the evolution of the sheared surface from the beginning of the tensile test until a major crack occurred. An interrupted tensile test was performed, during which high resolution images of the sheared edge were taken. The tensile test was performed in 5\% engineering strain increments. At the end of 5\% strain, the tensile test was halted, the lower grip was disengaged, and the sample clamped by the upper grip was moved in front of the camera. Both view directions to the sheared surface and to the burr side shown in Fig. 3 were captured by sequentially moving the sample in front of the video camera and capturing the front view of the sheared edge and the corner view of the burr. The images were analyzed to observe the evolution of the sheared surface during an interrupted tensile test. Performance of the material inside of the burr was investigated to confirm that the crack is developing from the tip of the burr rather than from the area of contact with the sharp edge of the tool. 


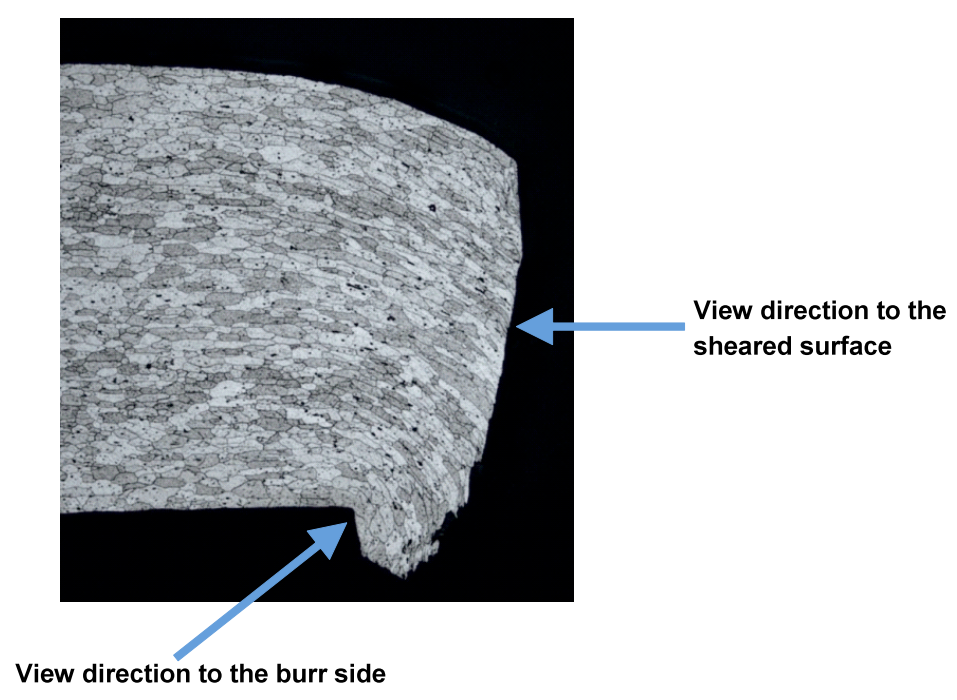

Figure. 3 Viewing directions of digital camera for methodology of fracture initiation study

The experimental setup shown in Fig. 4 illustrates the partial tensile test controlled by the software of MTS tensile test machine QTest 50 and the source of light utilized to illuminate sheared surface of tested specimens. The evolution of the fracture generated from the sheared surface was detected and collected by camera which was connected to a computer.

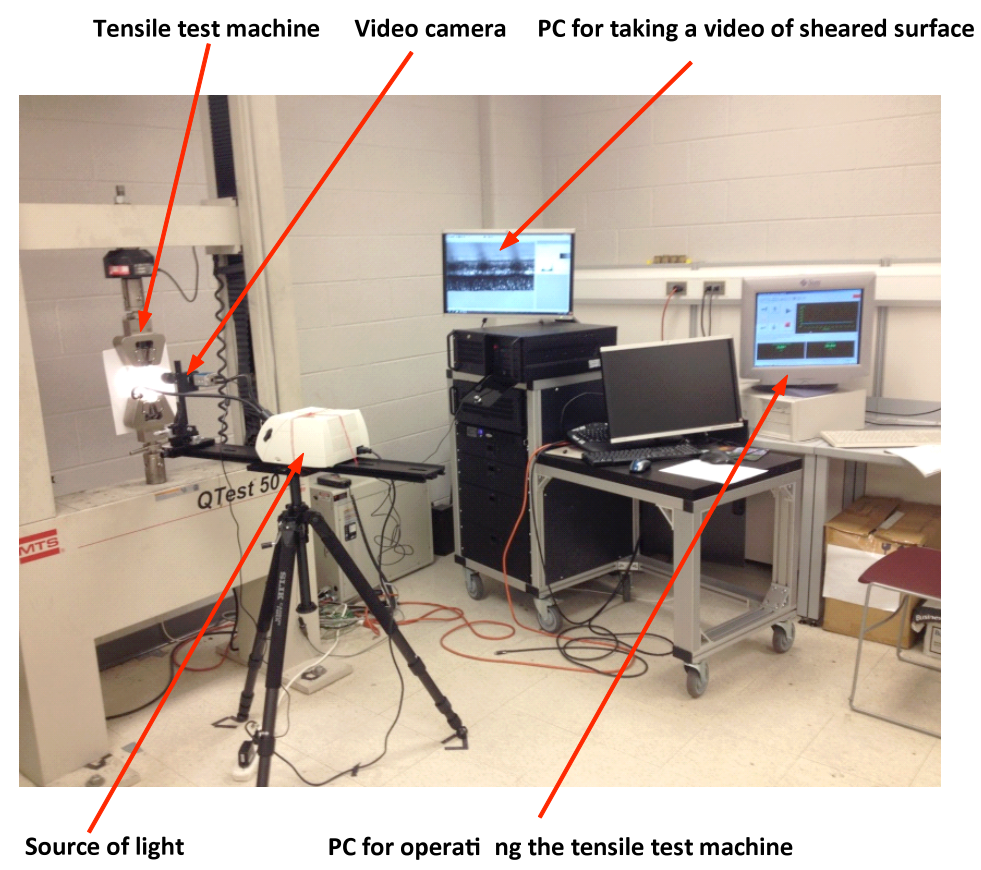

Figure. 4 Experimental setup used in methodology of fracture tracking. 
Monitoring of fracture initiation was initially conducted by taking a video of the sheared surface through the whole duration of the tensile test. In order to confirm that the crack did not initiate from the area of indentation of the lower shearing edge into the blank, additional series of videos were taken at a view direction to the burr side. However, since the video camera was stationary, and the sheared surface was moving, it was rather difficult to track back to the specific location of the sheared surface were crack initiated during the tensile test. Another difficulty was in gradual reduction of width of the sample leading to loss of sharpness of captured images. However, if focus of the image was adjusted during testing, it was possible to see the development of the crack from the burr tip.

After a number of iterations, the following sequence of steps was adopted: (1) specimen of the aluminum alloy employed in the study had one trimmed edge and metal finished other edge; (2) one surface of trimmed specimens was subsequently electro-etched to obtain $1 \mathrm{~mm}$ square grids to accurately locate the position of the crack; (3) the sample was clamped in the upper grip of the tensile test machine leaving the lower grip disengaged; (4) the upper grip raised, and the view of the initial sheared surface along the whole length of the strip was recorded as a sequence of pictures by the video camera; (5) a video of the initial sheared surface was subsequently compiled from the picture sequences by the computer software; (6) a video of the burr side was recorded along the whole length of the strip; (7) a video of the initial burr side surface was subsequently compiled from the picture sequences by the computer software; (8) the lower grip was engaged clamping the sample, and 5\% incremental stretching of the sample was conducted; (9) the new configuration of the sheared surface after applied 5\% of incremental stretching was recorded as a video followed by the same procedures as (4), (5), (6), (7) and (8) until crack formation; (10) by identifying the location of crack formation in the last video, images of that location from each video were compiled and analyzed.

\section{Discussion of experimental results on fracture mechanism during stretching of the sheared surface obtained by conventional trimming}

The distance between the crack and the selected grid line was measured, and the percentage of the distance to the whole length between two grid lines was 
calculated. Assuming that the interval between two adjacent grid lines deforms uniformly during the tensile test, the location of the source of fracture on the initial sheared surface can be identified, as it is illustrated in Fig.5.

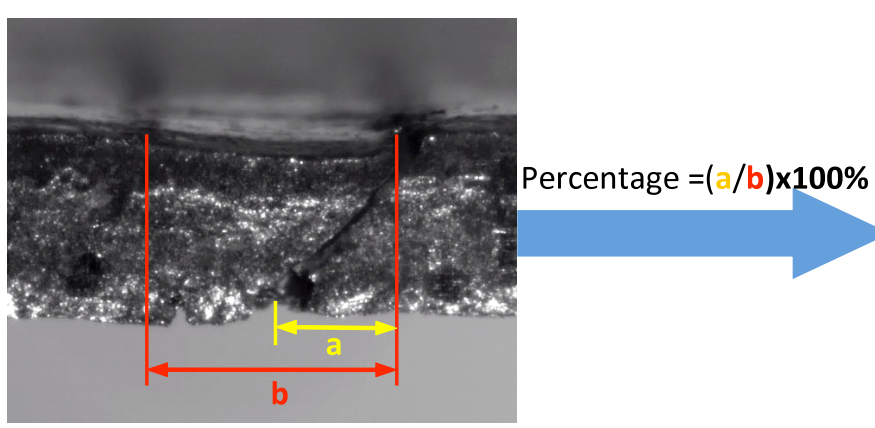

Almost fracture

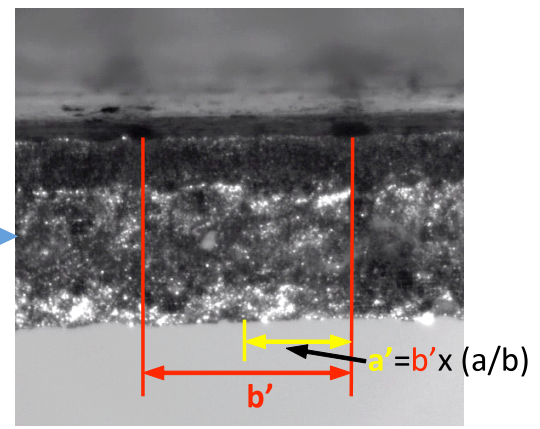

Initial

Fig. 5 Schematic of technique to coordinate the position where fracture initiating

Similar to previous studies of sheared edge stretchability in conventional trimming, stretching of the samples produced with accurate alignment of the upper and lower trimming steels with the clearance of $5 \%$ of sheet thickness effectively resulted in no burr along the trimmed edge with each sample experiencing failure mode 1 illustrated in Fig.6.

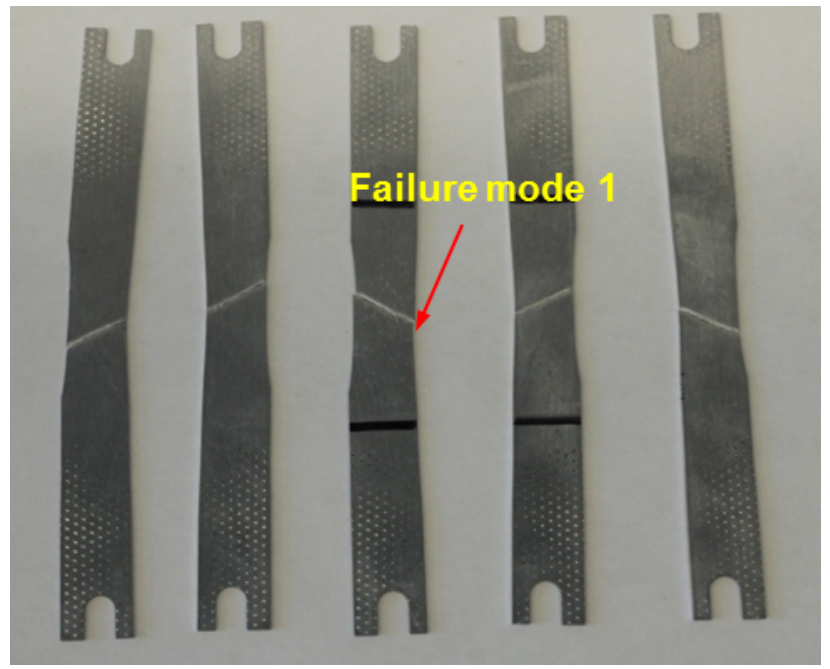

Figure. 6 Failure mode 1 of the sample conventionally trimmed with $5 \%$ clearance

Experimental analysis of fracture mechanism of specimens with 5\% clearance in conventional trimming was conducted according to the methodology described in the previous section. The thickness of the samples remains consistent along the length of the sample from the beginning of the test with no indication of localized necking until 15\% elongation (Fig.7). 
In Fig.7, Fig.8 and Fig.10, the black arrow points to the location of crack formation.

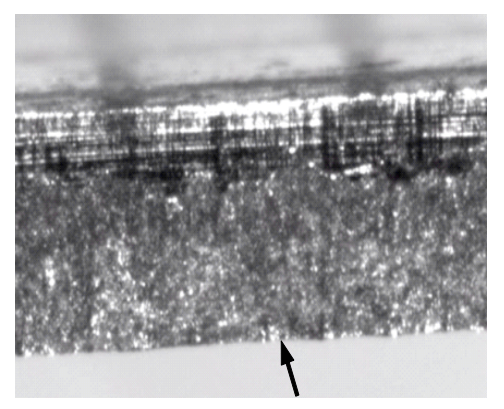

Initial

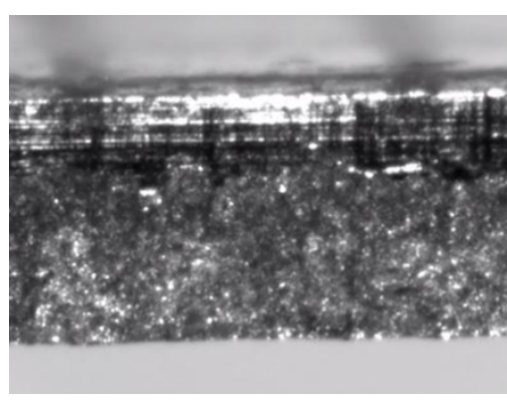

$5 \%$ stretching

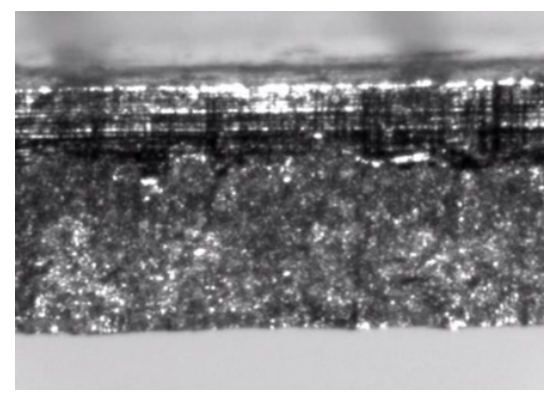

$10 \%$ stretching

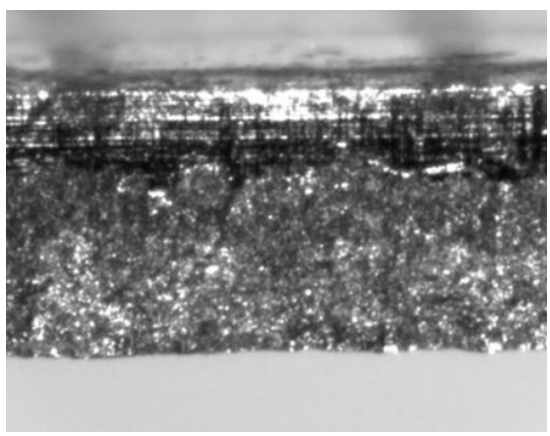

$15 \%$ stretching

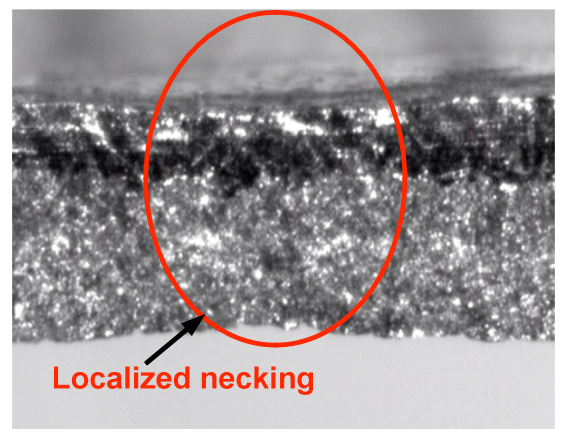

Localized necking

Figure. 7. Evolution of the fracture zone during stretching of the samples sheared by conventional trimming with $5 \%$ clearance.

For $10 \%$ clearance, the plastic deformation along the length of tested specimens is relatively uniform, and no significantly localized necking is observed prior to crack initiation. The sheared surface remains consistent from the beginning of the test until 10\% of stretching (Fig. 8). Even though no distinct burr on the trimmed edge was observed at this cutting clearance, all samples fractured in failure mode 2 as illustrated in Fig. 9. Localized necking was not observed prior to the fracture of the samples.
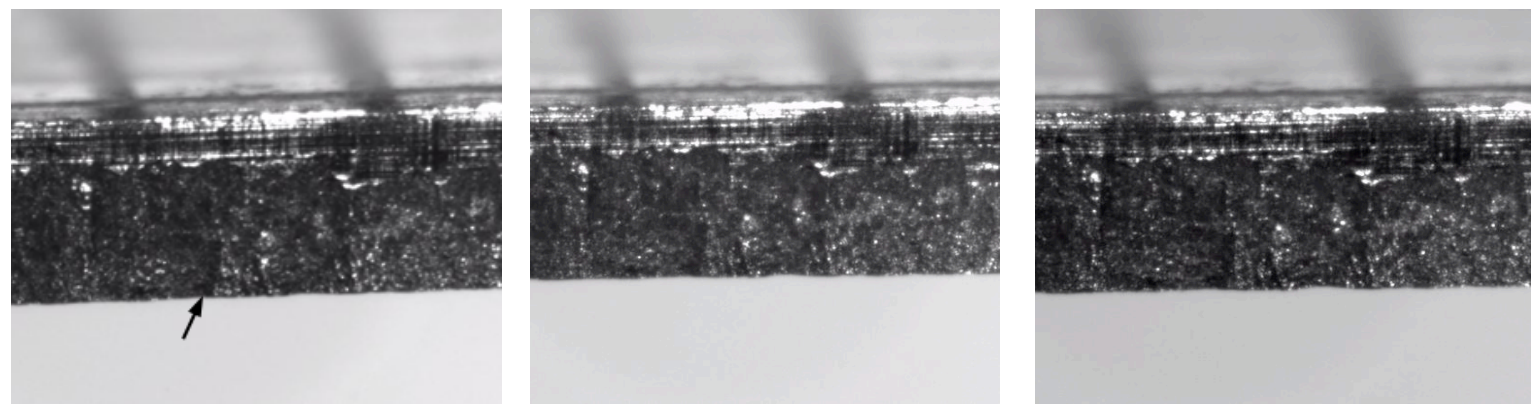


\section{Initial}

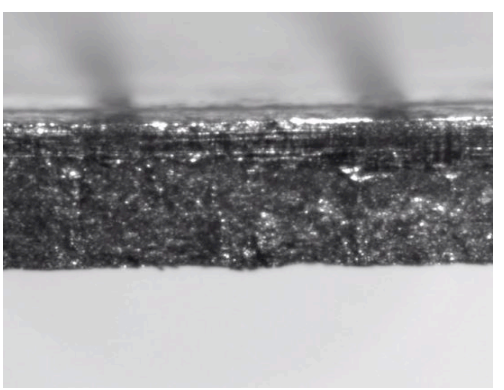

$15 \%$ stretching
$5 \%$ stretching

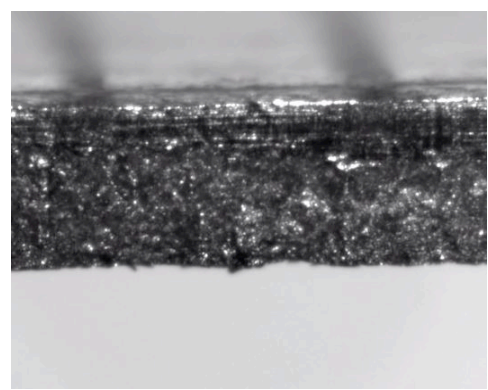

$20 \%$ stretching
$10 \%$ stretching

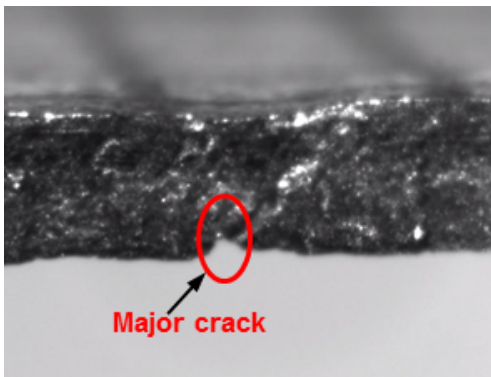

Almost fracture

Figure. 8 Evolution of the fracture zone during stretching of the samples sheared by conventional trimming with $10 \%$ clearance.

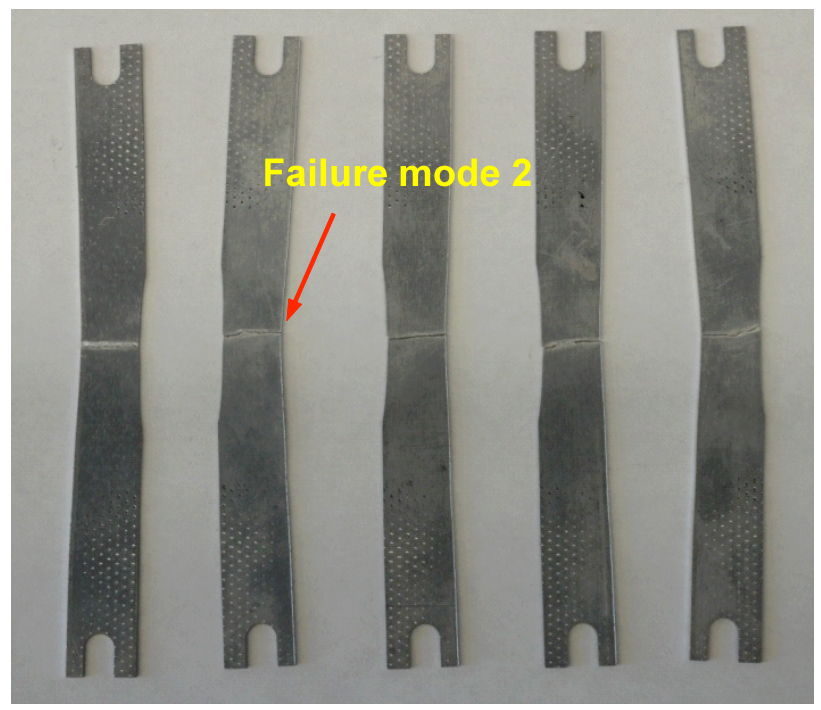

Figure. 9 Failure mode 2 of the sample conventionally trimmed with $10 \%$ clearance

Samples trimmed with a clearance from $15 \%$ to $40 \%$ fractured in failure mode 2 and had lower tensile elongations. Larger burrs were observed along the sheared edge after trimming with cutting clearances above $10 \%$. Detailed fracture mechanism of the sheared surface for these cases is illustrated in Fig.10.

Further experiments were conducted with the aluminum samples trimmed with $15 \%$ cutting clearance and then tensile tested following the procedure described above. As shown in Fig.10 (a), a consistent sheared surface from initial to $5 \%$ stretching was observed. However, a small crack appeared from 10\% stretching at lower edge of the sheared edge. Subsequently, the crack grew into a larger crack during stretching. At 15\% stretching, another small crack at the bottom of the sheared edge began to grow into a larger crack. In the last picture of 
Fig.10 (a), the fracture shows the major crack emerged from the lower spot which was associated with localized necking rather than the larger crack which appeared at $10 \%$ stretching. It indicated that, partially localized necking generated in the same location as the major crack which propagated from the burr area. Moreover, it demonstrated that multiple cracks existed on the sheared edge which was cut with $15 \%$ clearance by conventional trimming.

For the sample trimmed with 20\% clearance illustrated in Fig.10 (b), a distinct small crack emerged at 15\% stretching, and later developed into a major crack at 20\% stretching. No visible localized necking generated at the upper area of the sheared surface was observed. For the sample trimmed with $30 \%$ clearance shown in Fig.10 (c), multiple cracks were observed during stretching of the sheared surface which were propagating from the burr tip along the sheared edge.

In Fig.10 (d), substantial waviness of the sheared edge trimmed with $40 \%$ clearance was observed. This waviness was defined by a large variation in burr height along the sheared edge. A small crack appeared even at 10\% stretching, and it resulted in significantly lower sheared edge stretchability for this trimming configuration.

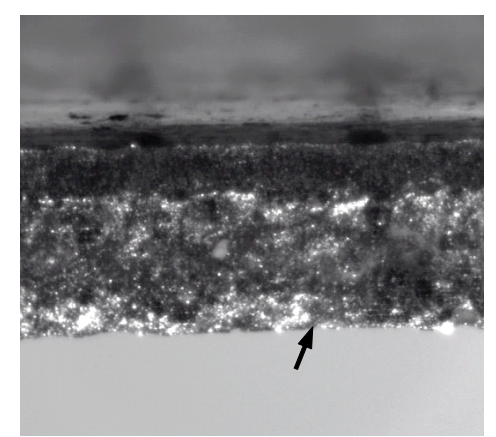

Initial

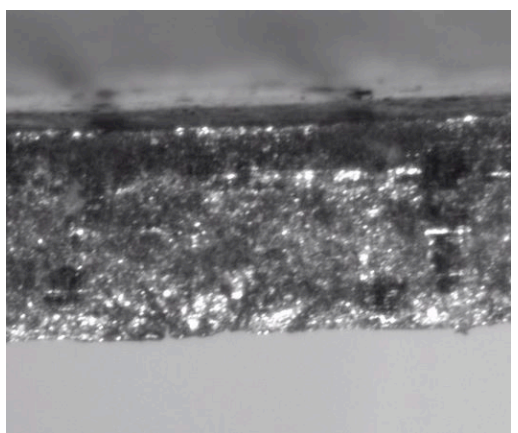

$5 \%$ stretching

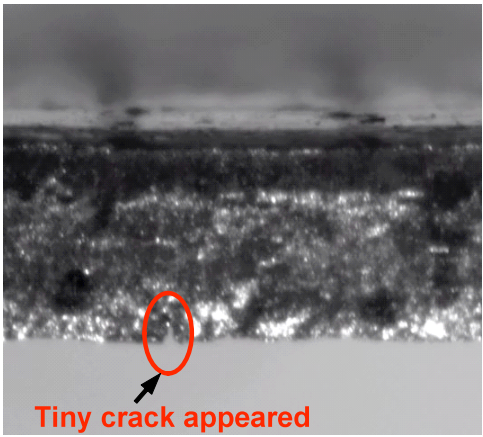

$10 \%$ stretching

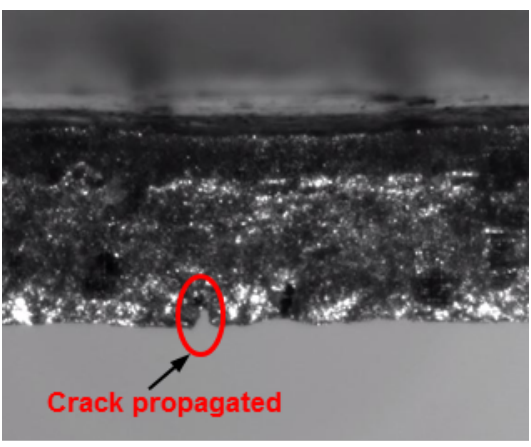

$15 \%$ stretching

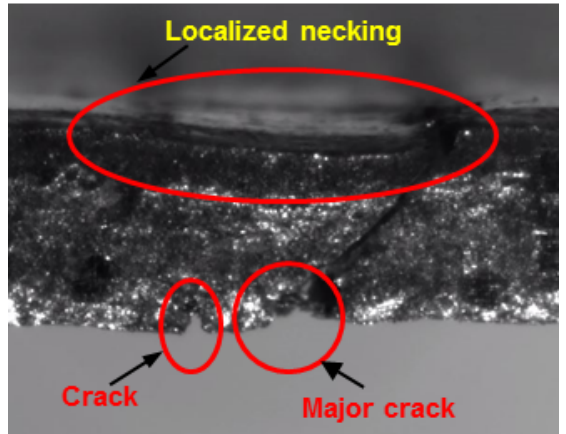

Almost fracture 
(a)

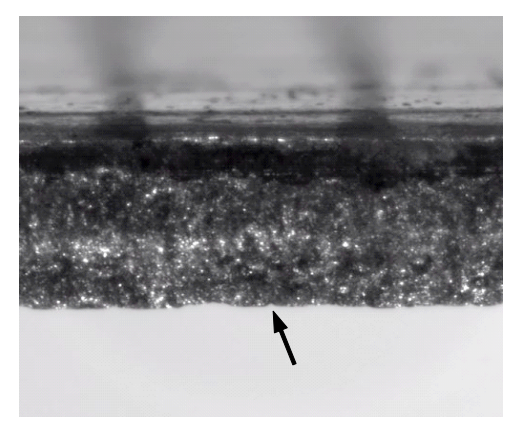

Initial

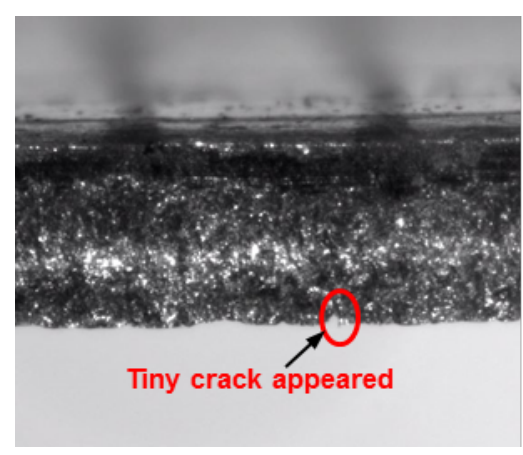

$15 \%$ stretching

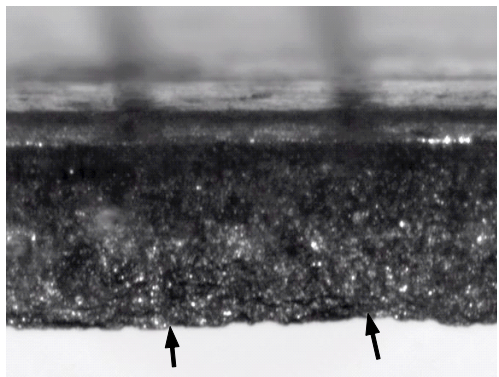

Initial

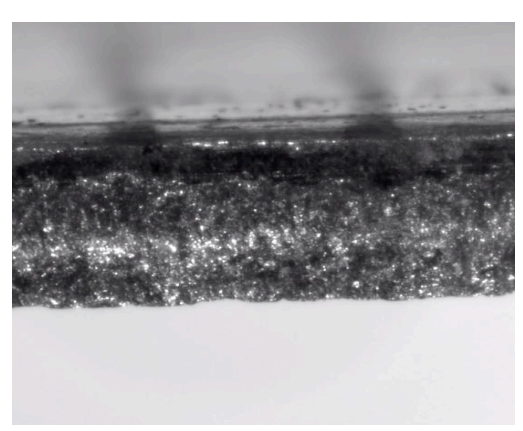

$5 \%$ stretching

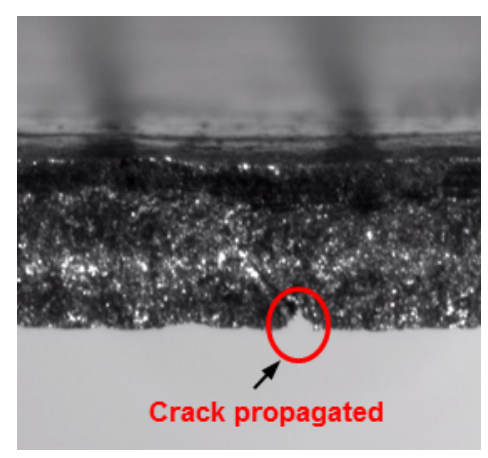

$20 \%$ stretching

(b)

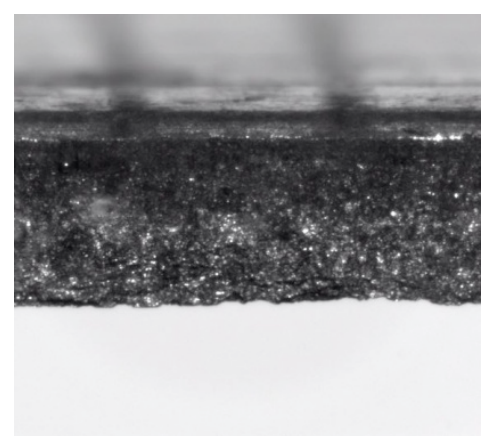

5\% stretching

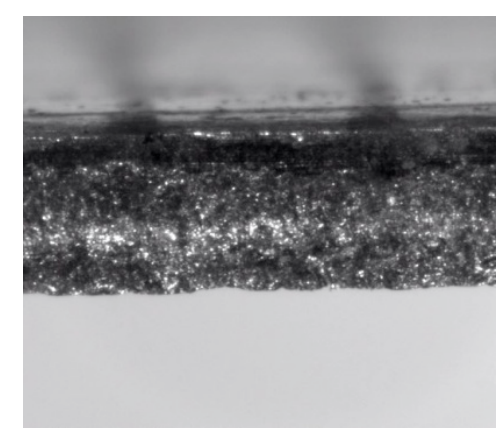

$10 \%$ stretching

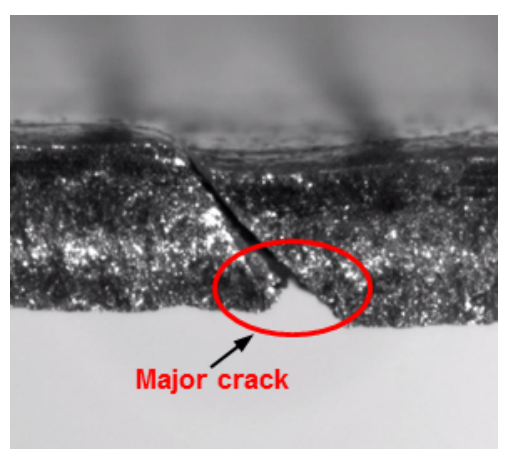

Almost fracture

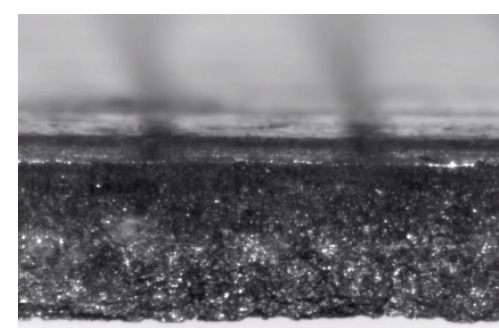

$10 \%$ stretching 


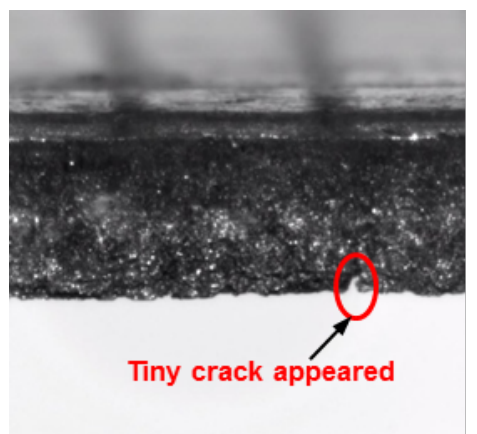

$15 \%$ stretching

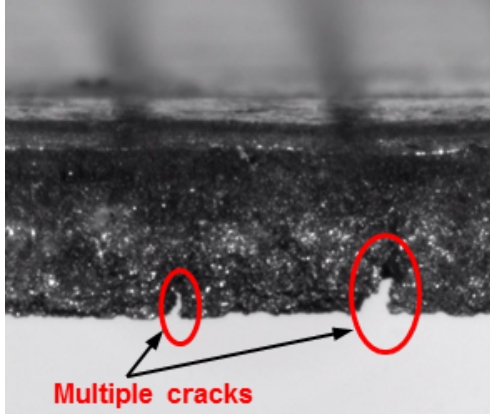

Almost fracture

(c)

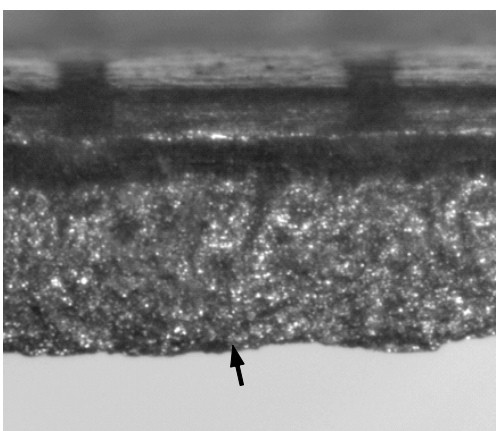

Initial

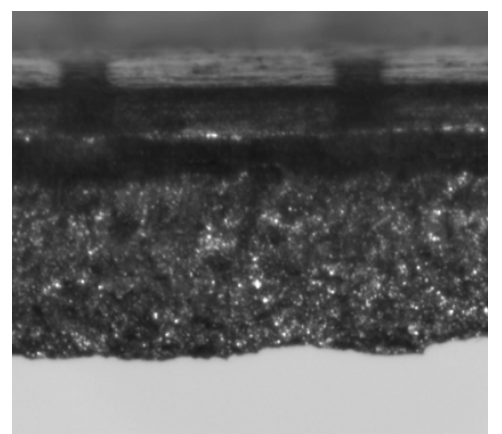

$5 \%$ stretching

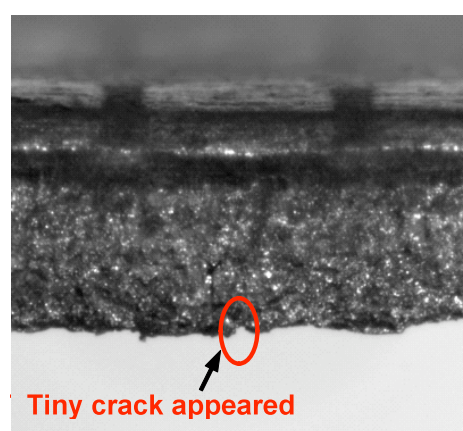

$10 \%$ stretching

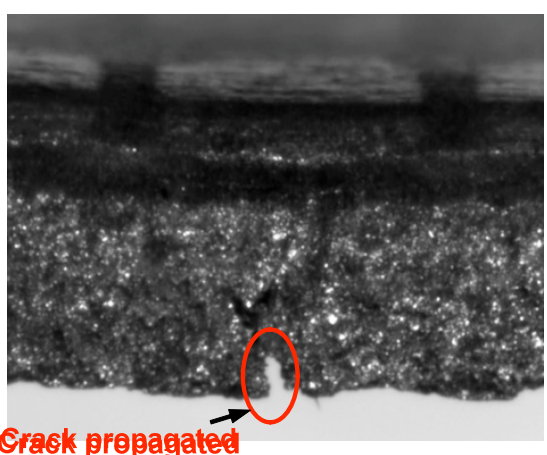

$15 \%$ stretching

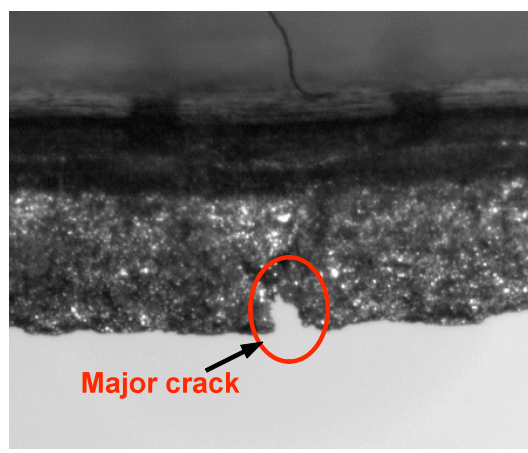

Almost fracture

(d)

Figure. 10 Pictures to track major crack with $15 \%$ (a), $20 \%$ (b), $30 \%$ (c) and $40 \%$ (d) clearance of conventional trimming viewed from direction to the sheared surface.

To further illustrate the initiation of fracture from the tip of the burr, an additional view direction from inside the burr shown in Fig. 3 was employed for the same sample which was used in Fig.10 (d). The reason to use the sample trimmed with $40 \%$ clearance is that the burr height for this clearance is the largest among all of the clearances analyzed in this study. The view of the burr can be 
distinctly observed in Fig.11. As mentioned above, the small crack generated from the tip of the burr was observed at $10 \%$ stretching which is corresponding to the picture shown in Fig.10 (d). Even though substantially higher strain is occurring in the area of the lower shearing edge and in the burnished area where the blank was in contact with the upper shearing edge, no fracture was observed in these areas of high strain. The fracture was repeatedly initiated from the tip of the burr, as it is illustrated in Fig. 11.

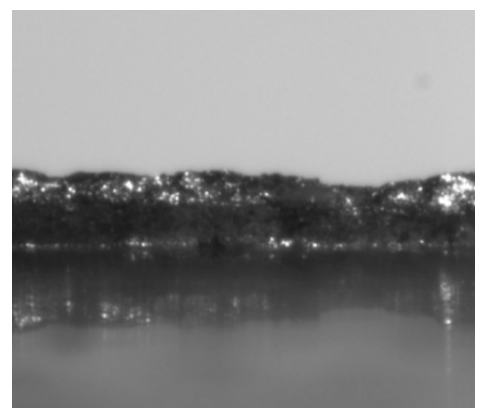

Initial

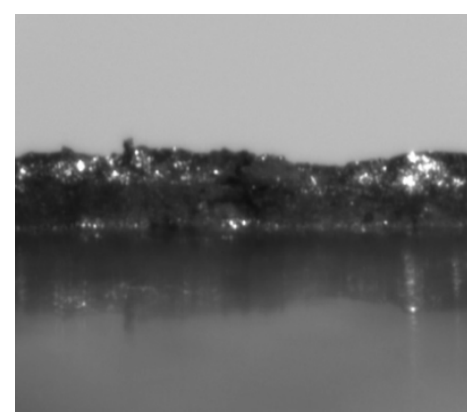

$5 \%$ stretching

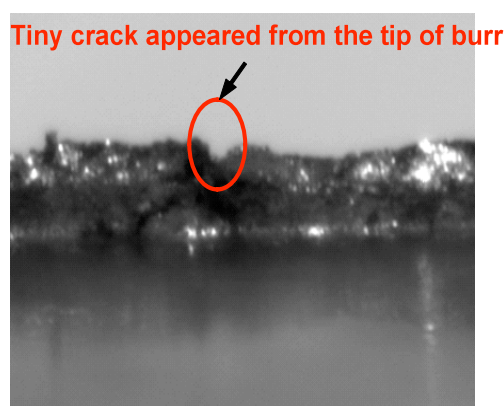

$10 \%$ stretching

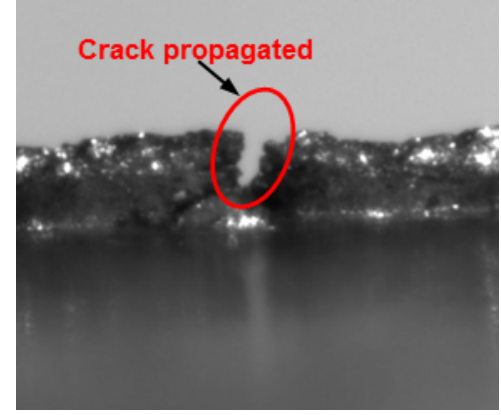

$15 \%$ stretching

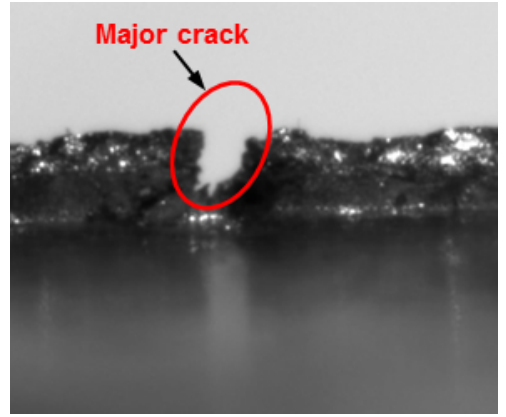

Almost fracture

Figure. 11 Pictures of fracture tracking of $\mathbf{4 0 \%}$ clearance with conventional trimming viewed from direction to the burr side.

\section{Analysis of factors influencing the fracture from the burr tip}

Influence of deburring on elongation with conventional trimming 


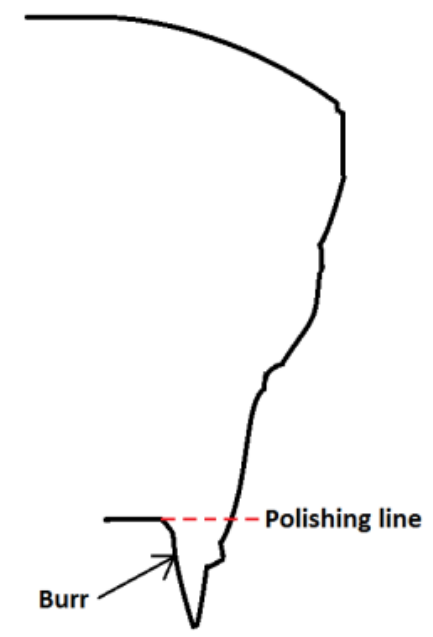

Figure. 12 Schematic of polishing line of deburring investigation.

Based upon investigation, the burr tip has been identified as a source of early fracture and reduced total elongation during stretching of the sheared edge. The burr height of samples sheared with $40 \%$ clearance with conventional trimming is significantly larger while total elongations of the samples trimmed with $40 \%$ clearance are substantially lower than those for other cutting clearances. Therefore, the samples produced with $40 \%$ cutting clearance were selected for further investigation of fracture mechanism.

One method to eliminate the split originating from the tip of the burr is to perform a deburring operation. Even though this approach is not attractive for long term correction of the sheared edge splitting problem in mass production conditions, it can be used as an urgent temporary measure when splits from the sheared edge suddenly originate, and an emergency production problem needs to be resolved quickly. In order to understand the effect of this temporary measure, the stretchability of $40 \%$ cutting clearance with and without deburring was compared. Five samples were stretched after trimming, and another five samples were deburred and then stretched. Deburring operation was accomplished by utilizing sandpaper with grit 320 to remove the burr along the sheared edge. All the samples stretched after trimming operation fractured in failure mode 2 with an elongation of $14.8 \% \pm 1.2 \%$ (mean \pm standard deviation). All deburred samples fractured in failure mode 1 with a total elongation of $22.1 \% \pm 0.9 \%$.

These results indicate that the total elongation of deburred specimens is substantially larger that of specimens which have burrs. It could be further seen that the elongations of deburred samples are close to the elongations of samples trimmed with $5 \%$ clearance. Those samples sheared with 5\% clearance were tensile tested and had a total elongation of $24.5 \% \pm 1.2 \%$. 


\section{Influence of roughness of sheared surface and partial removal of sheared surface on elongation with conventional trimming}

Roughness of the sheared surface is one of the factors which might play an essential role in the early fracture of the sheared edge. In a number of publications, researchers tried to smooth the sheared surface by shaving the sheared edge. Thipprakmas et al. (2008) studied the shaving process based upon FEM analysis in order to improve the quality of the sheared surface. Seo (2005) recommended a shaving procedure to improve stretchability of the sheared edge resulting in a higher HER.

Based upon observations of the sheared surface of the samples trimmed with various clearances, roughness of the surface trimmed with $5 \%$ clearance is significantly smoother than roughness after shearing with larger clearances. Elongations of samples sheared with $5 \%$ clearance are very similar to the elongations of the samples prepared for standard tensile testing experiments by machining or electrical discharge machining (EDM) technology. In order to check whether surface roughness is an important factor affecting the sheared edge stretchability, a short series of experiments was performed comparing stretchability of ten samples with 5\% clearance, five of which were artificially roughened after shearing by using sand paper with grit 80 .

Performed testing indicated that the elongation of the samples stretched after conventional trimming with $5 \%$ clearance was $24.5 \% \pm 1.2 \%$ with all the samples fractured in failure mode 1 . The roughened samples exhibited a total elongation of $23 \% \pm 1.5 \%$. The roughening procedure only decreased total elongation by $1.5 \%$. Therefore, the added roughness of sheared edge is not significant factor affecting stretchability along the sheared edge of aluminum alloy 6111-T4.

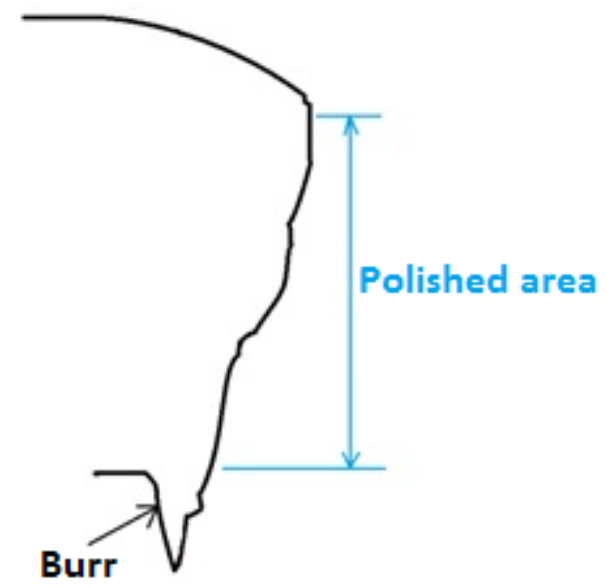

Figure. 13 Schematic of sheared surface with partially polished area. 
An attempt was made to separate the effect of the burr and the rest of the sheared surface on stretchability of the sheared edge. Five samples were sheared with $40 \%$ clearance in conventional trimming, and the sheared surface was polished using sandpapers with grit 280 and 600 while preserving the original burr (Fig. 13). Tensile testing of these samples revealed the total elongation $14.6 \% \pm$ $0.7 \%$ while the average total elongation of samples stretched after trimming with $40 \%$ clearance and no further polishing was $14.8 \% \pm 1.2 \%$.

\section{Stretchability of the sheared edge}
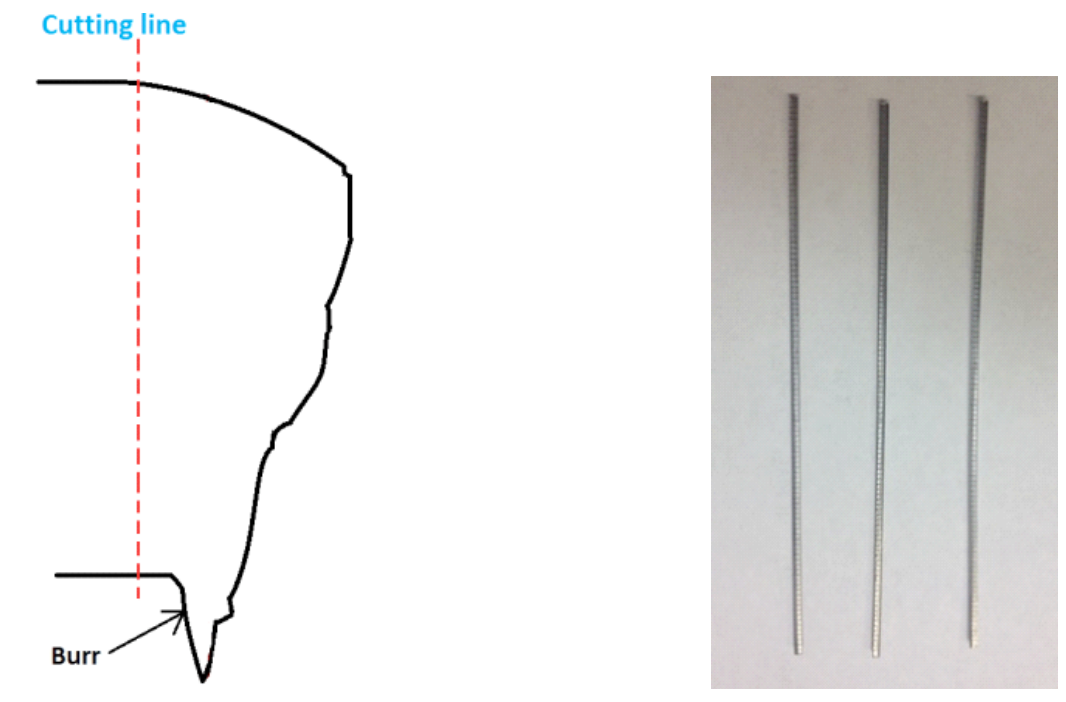

Figure. 14 Schematic of cutting line for fabrication of narrow specimens (left) and the narrow specimens with $1 \mathrm{~mm}$ square grids (right).

In order to study stretchability of the sheared edge separate from the adjacent non-deformed material, an additional set of experiments was performed. Narrow specimens were prepared by cutting off sheared edges initially fabricated with $40 \%$ clearance and subsequently tensile tested. The method of preparation of samples for this section is illustrated in Fig. 14 where dashed line shows where the secondary shearing was performed. In order to avoid fracture from this secondary sheared surface, the secondary cut was performed with $5 \%$ clearance. The width of these narrow samples was approximately $1.5 \mathrm{~mm}$.

In this sample configuration, there was less material behind the burr to delay propagation of the major crack. Prior to fabrication of these narrow specimens, $1 \mathrm{~mm}$ square grids were electro etched on one surface of the original wider samples. During tensile testing of the narrow specimens, fracture always started from the tip of the burr, and all the samples fractured in failure mode 2 with $9.4 \%$ $\pm 1.9 \%$ total elongation. 
The narrow specimens containing the sheared surface with the burr had substantially lower elongations compared to the results for the samples sheared in similar conditions which were $12.7 \mathrm{~mm}$ wide. This can be explained by the observations of initial cracks from the burr tip of the sheared surface illustrated in Fig.10 (d) where fracture was initiating at approximately $10 \%$ of total elongation. It can be anticipated that cracks propagate more easily if there is less non-deformed material around the burr.

\section{Stretchability of sheared samples after solution heat treatment}

Theoretically, work hardening (strain hardening) and residual stresses are natural consequences of cold working such as stamping or trimming operations. These consequences might be eliminated by thermal treatment techniques such as solution heat treatment. The mechanism of solution heat treatment is to heat aluminum alloy at eutectic temperature followed by rapid quenching method to hold all solid solutes in equilibrium situation, as it is recommended by Hatch (1984). Consequently, material microstructure will be rather close to original material undeformed by cold working.

The aluminum alloy 6111-T4 employed in the study is a heat treatable aluminum alloy $(0.75 \% \mathrm{Mg}, 0.85 \% \mathrm{Si}, 0.7 \% \mathrm{Cu}, 0.25 \% \mathrm{Fe}$, and $0.30 \% \mathrm{Mn})$. The temper designation $\mathrm{T} 4$ indicates the material has been solution heat treated and naturally aged to a substantially stable condition. Hence, aging at room temperature (natural aging) was utilized as an essential procedure after quenching for aluminum alloy sheet employed in this investigation.

Since silicon and magnesium are predominated components in aluminum alloy $6111-\mathrm{T} 4$, a suitable temperature $560^{\circ} \mathrm{C}\left(1040^{\circ} \mathrm{F}\right)$ was utilized to put the maximum practical amount of these hardening solutes in the aluminum matrix. Generally, thin aluminum alloy sheet might require only a few minutes of quenching. Based upon the dimensions of tested specimen which only has $0.9 \mathrm{~mm}$ thickness and $12.7 \mathrm{~mm}$ width, ten minutes was utilized to hold tested specimens at eutectic temperature.

After heat treatment, tensile testing of samples was performed: Failure mode 1 was observed for all of the specimens. Total elongation was $23.1 \% \pm 1.2 \%$ which is substantially larger than the elongations observed for similar samples without heat treatment. An increase in elongation compared to samples trimmed with accurate alignment and discussed further in Section 7 can be related to the change of temper of the overall material. However, the shift from failure mode 2 to failure mode 1 in all the samples serves as an indication that the effect of sheared edge was eliminated as a result of heat treatment, and that geometry of the burr makes 
no difference on the trimmed sample stretchability if the effect of cold work is eliminated.

\section{Comparison of experimental results on elongation with scrap support and conventional trimming}

Since the tip of the burr is identified as a major source of early fracture, and a trimming process with scrap support described by Golovashchenko (2006) is capable of eliminating burrs for broad range of cutting clearances, the stretchability of material sheared with scrap support was studied in this section. A schematic of the trimming process with scarp support is shown in Fig. 15.

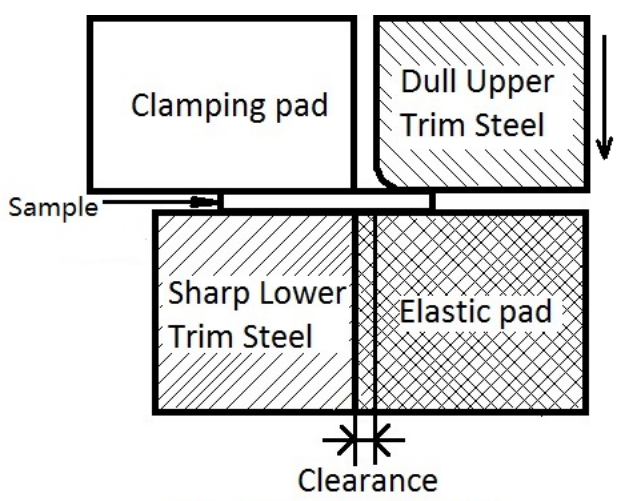

Figure. 15 The schematic of trimming process with scarp support

The upper trim steel had a small radius of approximately $0.1 \mathrm{~mm}$ on the trim edge in order to suppress fracture initiation from the upper trim steel. The elastic pad underneath the blank prevents the scrap from bending and creating stretching conditions on the upper surface of the blank.

Similar to conventional trimming, the samples were clamped between the clamping pad and the lower trim steel. Both upper and lower trim steels were mounted on the die shoe to provide an accurate and stable cutting clearance.

The range of clearances between the shearing edges in the study was established between $5 \%$ and $40 \%$ of material thickness, as it was done in the previous study for conventional trimming by Le et al. (2013). The samples were sheared in three directions relative to rolling direction: parallel to the longitudinal (LD), transverse (TD) and diagonal $\left(45^{\circ}\right)$ (DD). 
The major strains of half dog-bone tensile test in longitudinal direction (LD) listed in Table 1 and provide full details on measurement of individual ellipses.

With 5\% clearance samples trimmed conventionally and samples sheared with scrap support exhibit similar values of safe and total elongations during tensile testing along the sheared edge. About half of the samples fractured in failure mode 1 while the other half fractured in mode 2 or in combination of modes 1 and 2 but really provided similar elongations as in the failure mode 1 . For $10 \%$, $15 \%$ and $20 \%$ clearances, the situation is very similar. For larger clearances such as $30 \%$ and $40 \%$, the safe and total elongations decrease, and all the samples exhibit fracture in failure mode 2.

Table 1 Major strains measured for ellipses according to schematic in Fig.2 for LD samples trimmed from as-received material with scrap support.

\begin{tabular}{|c|c|c|c|c|c|c|c|}
\hline Clearance & $\begin{array}{l}\text { Sample } \\
\text { Number }\end{array}$ & Type I & Type II & Type III & Type IV & $\begin{array}{l}\text { T.E. } \\
(\%)\end{array}$ & $\begin{array}{l}\text { Failure } \\
\text { Mode }\end{array}$ \\
\hline & 1 & 46.2 & & 26.7 & 26.3 & 22.9 & 2 \\
\hline & & & & 31.3 & & & \\
\hline & 2 & 39.6 & & 23 & 22.4 & 19.4 & $2+1$ \\
\hline & & & & 29.8 & & & \\
\hline \multirow[t]{10}{*}{$5 \%$} & 3 & & 33.1 & & 25.5 & 23.2 & 1 \\
\hline & & & 41.3 & & & & \\
\hline & 4 & 34.5 & & 26.8 & 23.4 & 22.6 & 2 \\
\hline & & & & 28.4 & & & \\
\hline & 5 & & 31.3 & & 27.4 & 23.8 & 2 \\
\hline & & & 35.9 & & & & \\
\hline & 1 & 46.4 & & 28.2 & 21.8 & 21.3 & 1 \\
\hline & & & & 26.7 & & & \\
\hline & 2 & 36.6 & & 33.8 & 23.5 & 24.3 & 1 \\
\hline & & & & 28.8 & & & \\
\hline \multirow[t]{10}{*}{$10 \%$} & 3 & 49.1 & & 29.3 & 20.4 & 23.0 & 1 \\
\hline & & & & 27.8 & & & \\
\hline & 4 & & 35.8 & & 22.5 & 23.4 & 2 \\
\hline & & & 30.9 & & & & \\
\hline & 5 & & 35.9 & & 17.6 & 21.0 & 2 \\
\hline & & & 25.8 & & & & \\
\hline & 1 & 48.9 & & 26.9 & 23.3 & 20.9 & 1 \\
\hline & & & & 32.1 & & & \\
\hline & 2 & & 32.1 & & 24.2 & 24.8 & 1 \\
\hline & & & 35.6 & & & & \\
\hline \multirow[t]{3}{*}{$15 \%$} & 3 & 36.3 & & 27 & 26.8 & 23.5 & 2 \\
\hline & & & & 28.8 & & & \\
\hline & 4 & & 29.1 & & 21.8 & 22.6 & 2 \\
\hline
\end{tabular}




\begin{tabular}{|c|c|c|c|c|c|c|c|}
\hline \multicolumn{8}{|c|}{36.7} \\
\hline & 5 & 34.9 & & 25.7 & 21.8 & 20.9 & 2 \\
\hline & & & & 24.2 & & & \\
\hline & 1 & 42.7 & & 30.4 & 22.3 & 20.9 & 1 \\
\hline & & & & 27.4 & & & \\
\hline & 2 & & 35.5 & & 24.6 & 23.5 & 1 \\
\hline & & & 34.5 & & & & \\
\hline \multirow[t]{9}{*}{$20 \%$} & 3 & 29.3 & & 22.1 & 23.2 & 21.8 & 2 \\
\hline & & & & 26.5 & & & \\
\hline & 4 & 39 & & 27 & 22.1 & 22.1 & 1 \\
\hline & & & 37.5 & 26.6 & & & \\
\hline & 5 & & 36 & & 27.7 & 25.3 & 1 \\
\hline & 1 & 27.2 & & 15 & 17.7 & 16.3 & 2 \\
\hline & & & & 17.9 & & & \\
\hline & 2 & 28 & & 13.4 & 15.4 & 20.8 & 2 \\
\hline & & & & 20 & & & \\
\hline \multirow[t]{10}{*}{$30 \%$} & 3 & 24.3 & & 17.1 & 16.2 & 15.3 & 2 \\
\hline & & & & 15.8 & & & \\
\hline & 4 & 28.8 & & 17.5 & 19 & 15.7 & 2 \\
\hline & & & & 15.9 & & & \\
\hline & 5 & & 28.8 & & 20.2 & 20.0 & 2 \\
\hline & & & 24.2 & & & & \\
\hline & 1 & 30.9 & & 20 & 21 & 20.7 & 2 \\
\hline & & & & 20.2 & & & \\
\hline & 2 & & 26.8 & & 20.6 & 21.5 & 2 \\
\hline & & & 27.4 & & & & \\
\hline \multirow[t]{6}{*}{$40 \%$} & 3 & 24.8 & & 14.3 & 18.2 & 17.2 & 2 \\
\hline & & & & 16.7 & & & \\
\hline & 4 & 26.2 & & 25.7 & 19.9 & 21.8 & 2 \\
\hline & & & & 19.9 & & & \\
\hline & 5 & 28.9 & & 18.6 & 21 & 20.3 & 2 \\
\hline & & & & 19.8 & & & \\
\hline
\end{tabular}

The results of local strain measurements from Table 1 were compiled into a graph shown in Fig. 16. In general, it was following the approach developed for Forming Limit Diagrams, as described in Hecker, S.S. (1975). This approach does not average the data points and does not define the error bars as standard deviation. It separates the fractured and localized ellipses from safe ellipses. The uncertainty bar in Fig.19 might be considered as a distance between the lowest major strain value of the fractured or localized ellipses and the highest value of major strain 
value of the safe ellipses. Therefore, the uncertainty should be above the data point as illustrated in Fig.19 rather than shown symmetrically.

The safe forming limit curves were determined by the maximum elongation between Type III and Type IV ellipses of each clearance, and the fracture curves were defined by the minimum elongation between Type I and Type II ellipses of each clearance. Filled or open symbols of local strains displayed in the figure indicate samples experiencing failure mode 1 or 2 respectively. Similarly, local strains of half dog-bone samples with transverse and diagonal rolling directions after stretching were compiled into graphs shown in Fig. 17 and Fig.18.

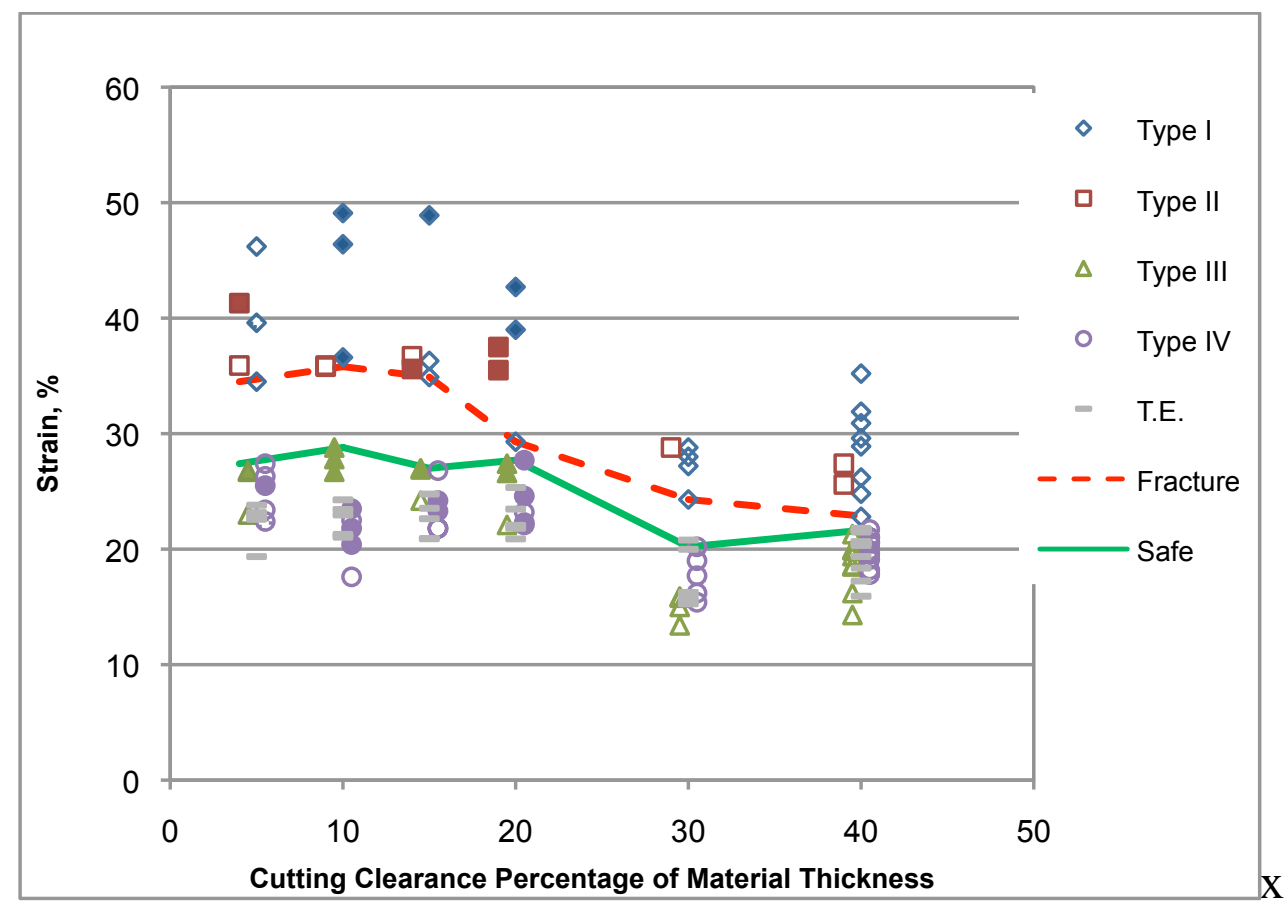

Figure. 16 Elongation of sheared surface trimmed with scarp support and tensile direction parallel to LD for $0.9 \mathrm{~mm}$ thick as-received 6111-T4 sheet. 


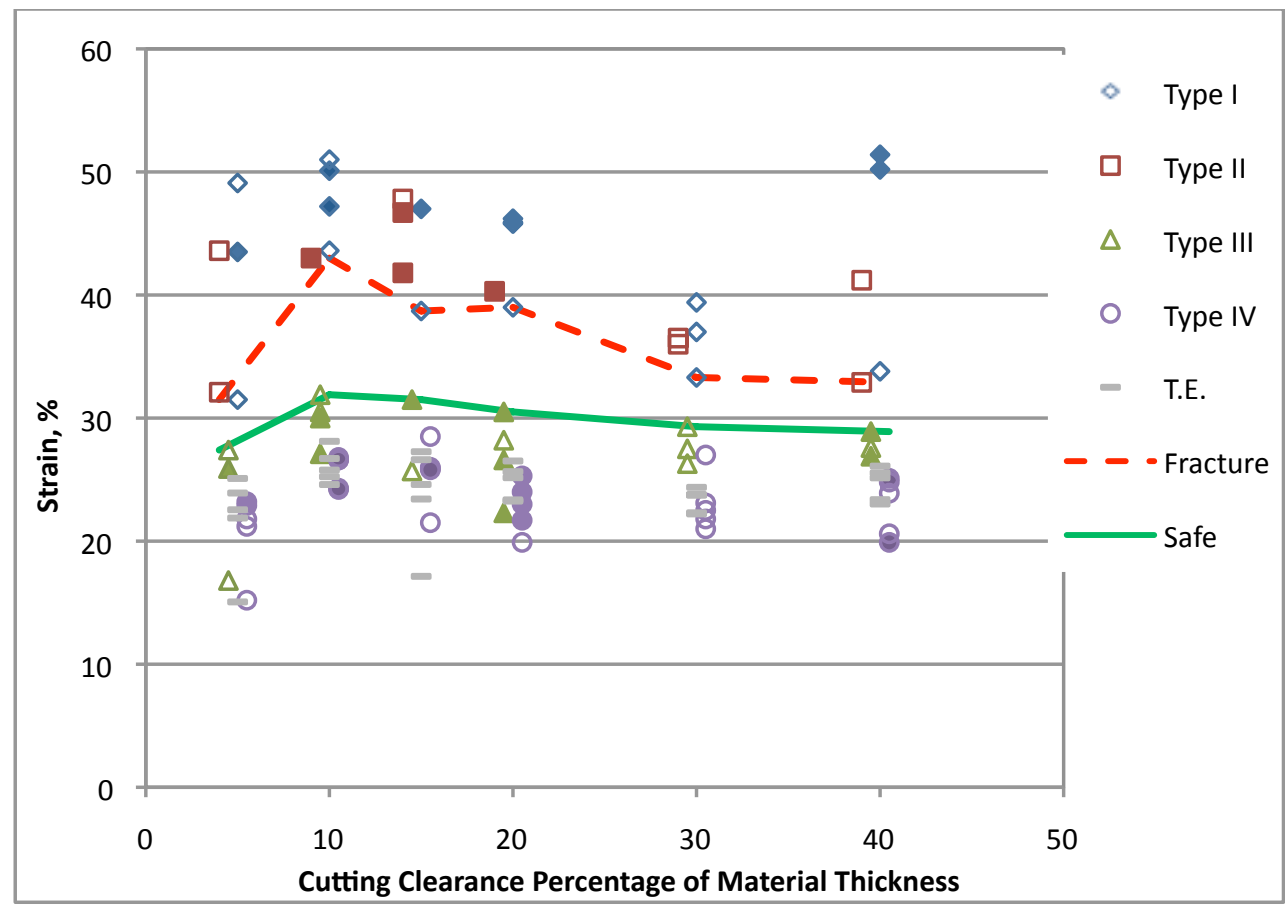

Figure. 17 Elongation of sheared surface trimmed with scrap support and tensile direction parallel to TD for $0.9 \mathrm{~mm}$ thick as-received 6111-T4 sheet.

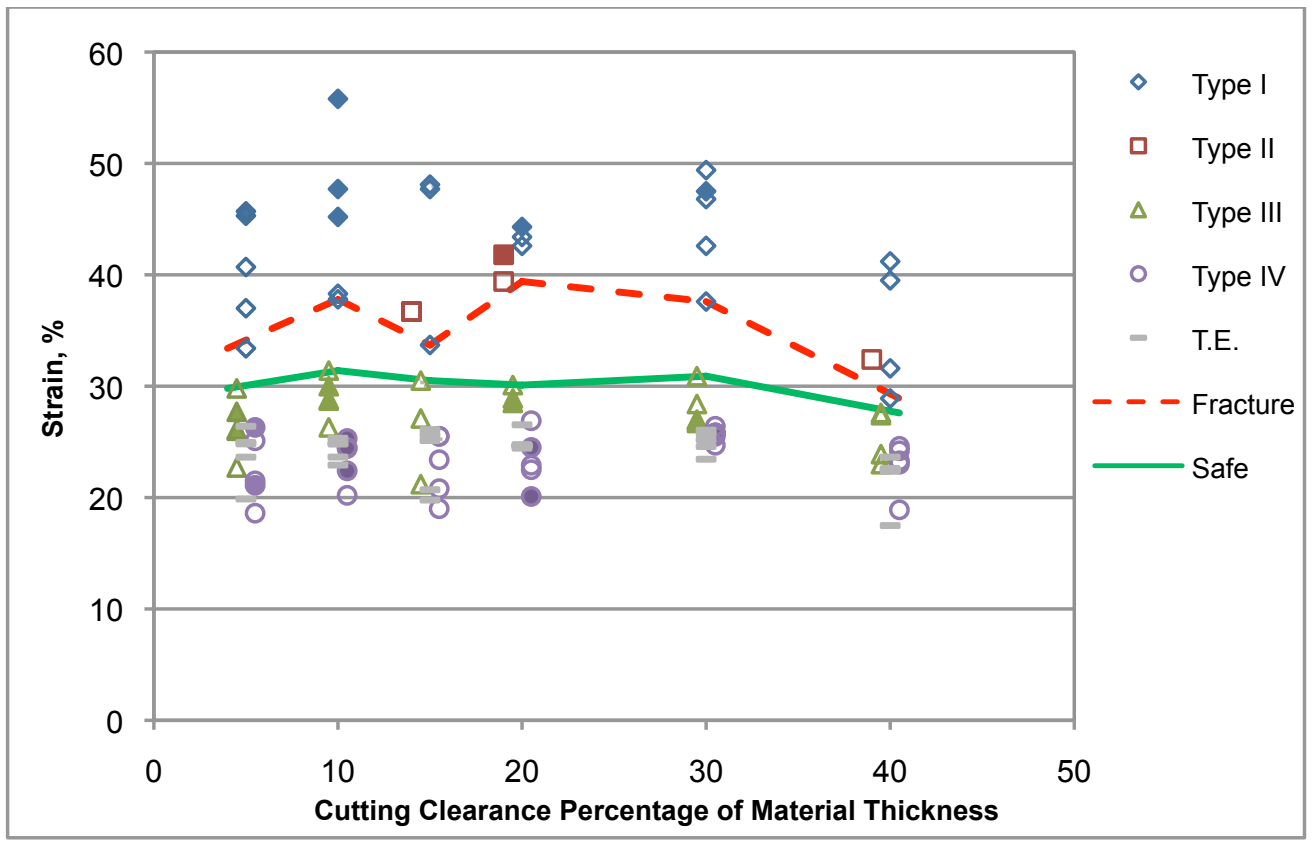

Figure. 18 Elongation of sheared surface trimmed with scrap support and tensile direction parallel to DD for $0.9 \mathrm{~mm}$ thick as-received 6111-T4 sheet.

A graphical comparison of the safe forming limit curves of half dog-bone samples under both trimming conditions corresponding to three rolling directions is illustrated in Fig. 19. 
For 5\% and 10\% clearances, safe formability limit of trimming process with scrap support is close to the formability limit of conventional trimming. For clearances exceeding 15\%, substantially larger elongations were observed for samples trimmed with scrap support. The cross-sections of half dog-bone samples trimmed with scrap support in LD, TD and DD directions are shown in Fig.20. No burrs were observed on the sheared surface in the range of cutting clearances from $5 \%$ to $40 \%$ in rolling, transverse and diagonal directions. It indicates that application of trimming process with scrap support effectively eliminates bending of the offal and prevents burr generation during trimming operation. This confirms the trend that elimination of the burr from the sheared edge in a wide variety of clearances helps to substantially improve stretchability of the sheared edge.

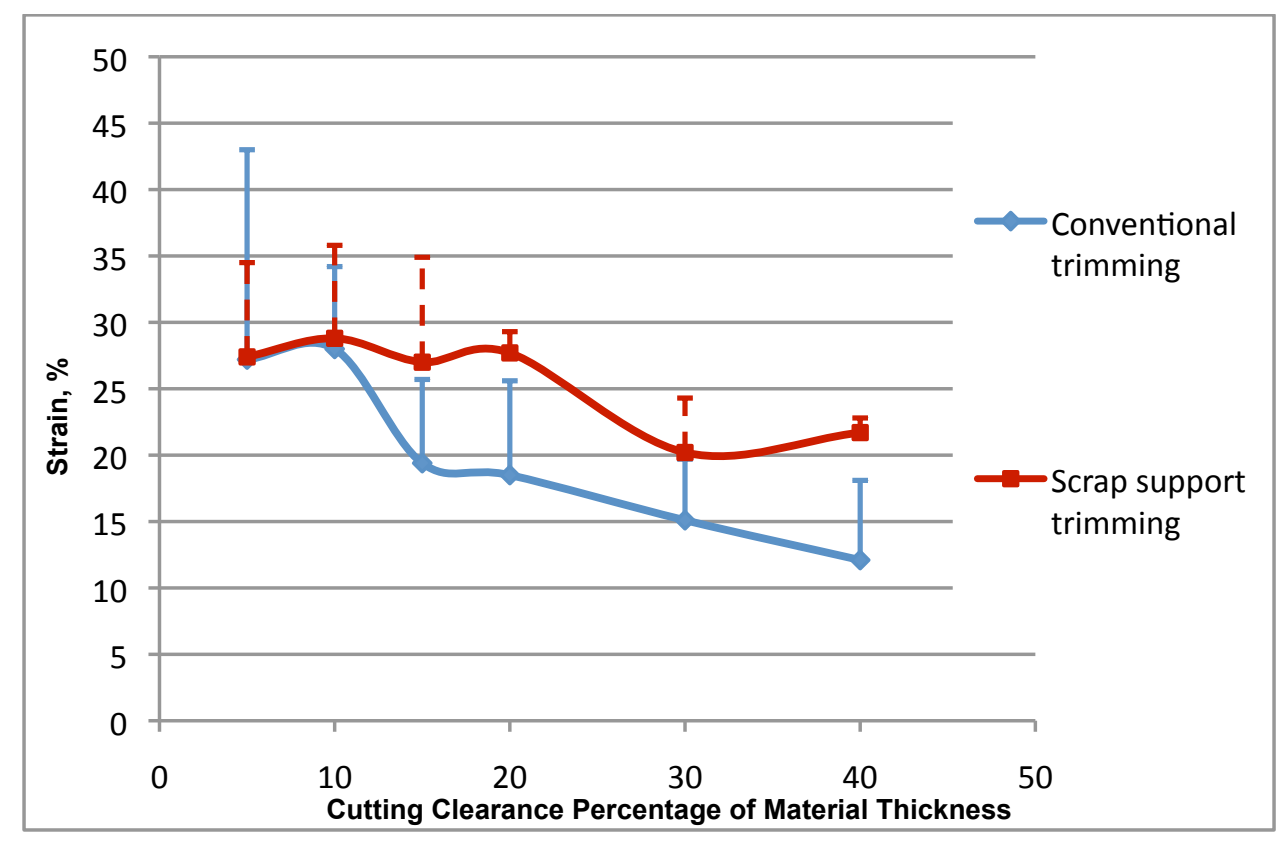

(a) 


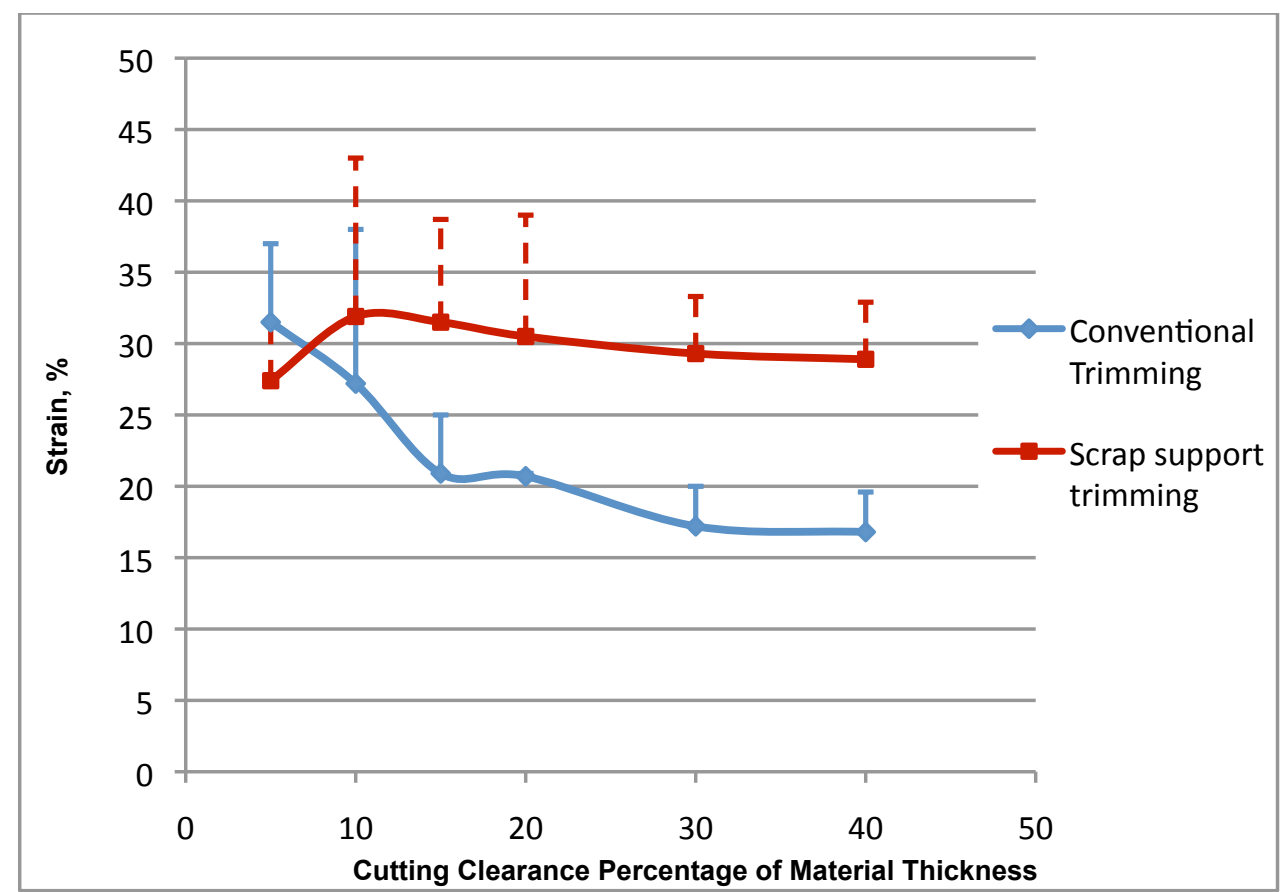

(b)

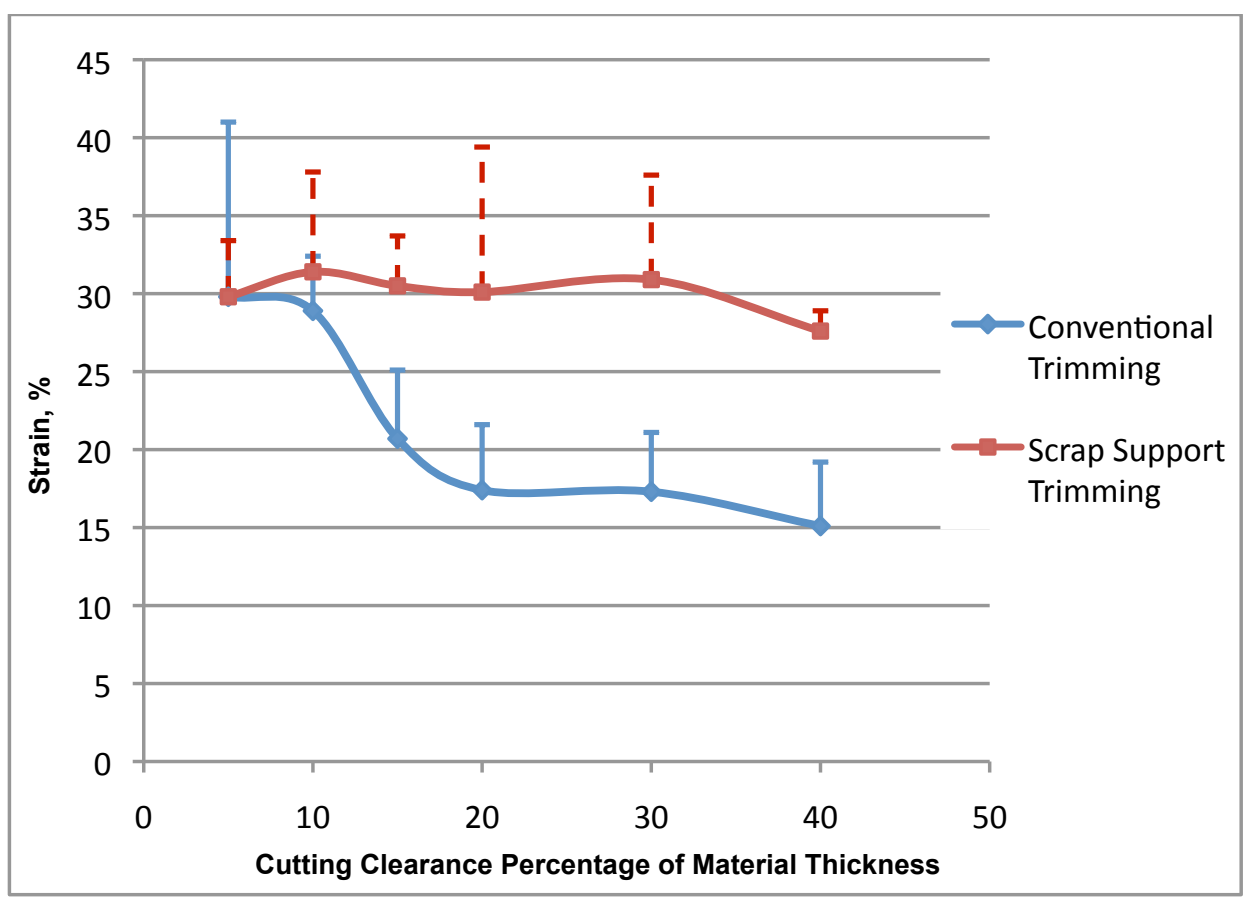

(c)

Figure. 19 Comparison of elongation for trimming process with scrap support, and conventional trimming process in (a) LD, (b) TD and (c) DD directions. 


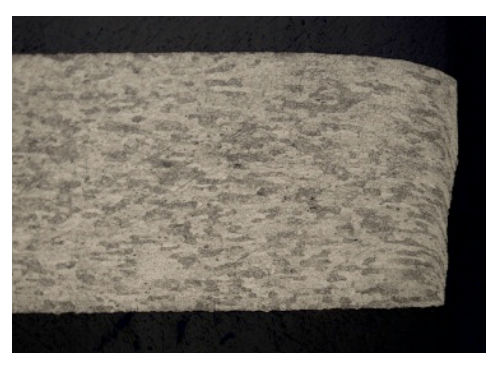

$5 \%$ clearance

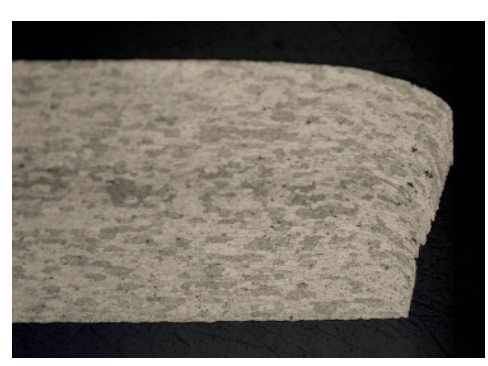

$20 \%$ clearance

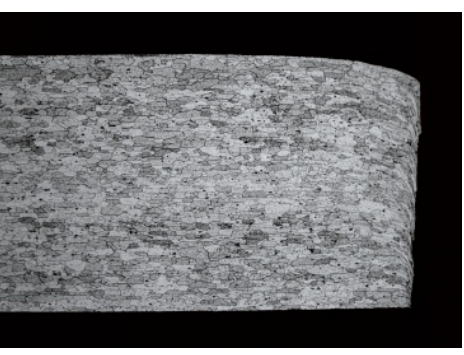

$5 \%$ clearance

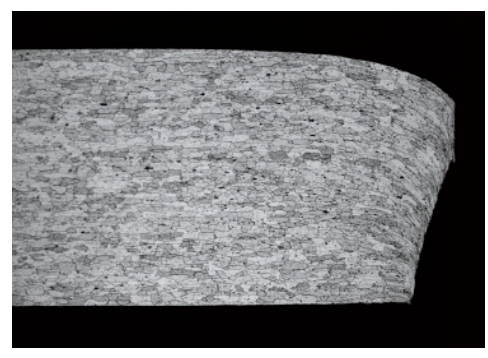

$20 \%$ clearance

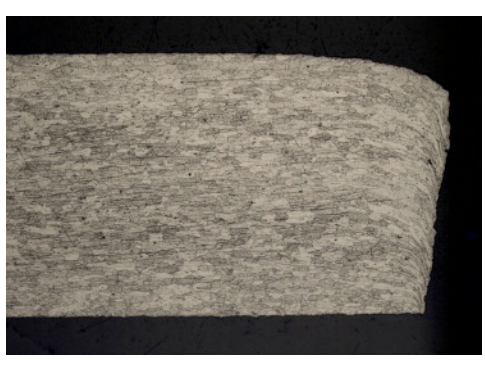

$10 \%$ clearance

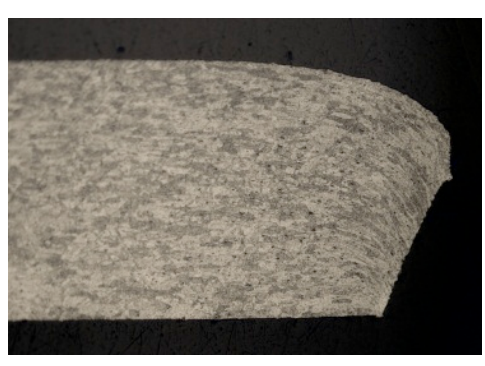

$30 \%$ clearance

(a)

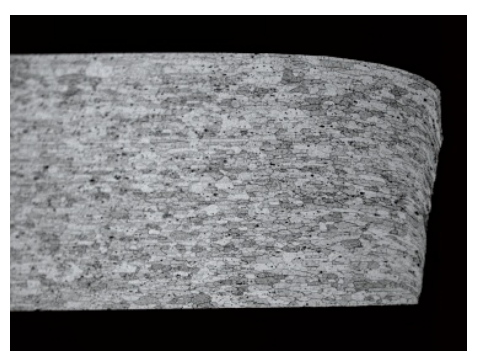

$10 \%$ clearance

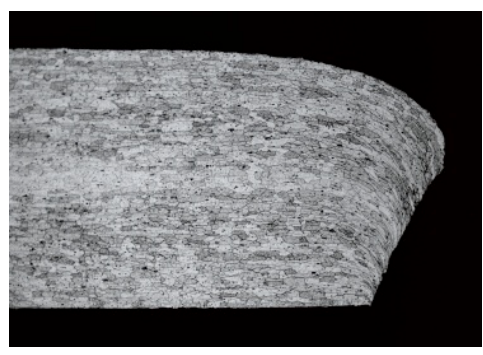

$30 \%$ clearance

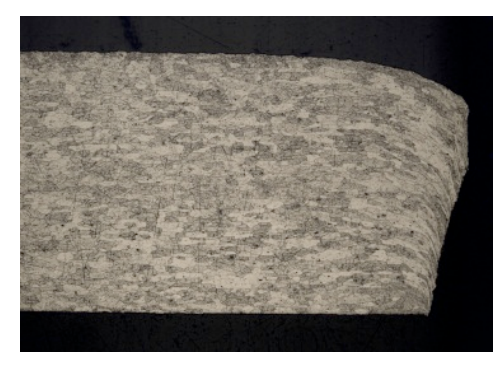

$15 \%$ clearance

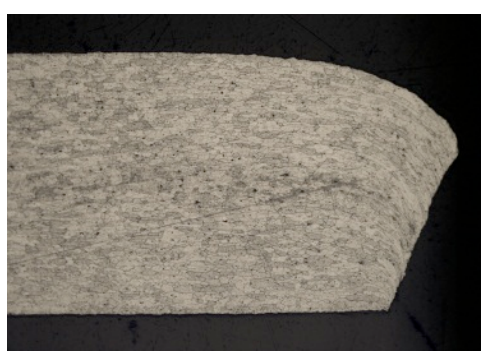

$40 \%$ clearance

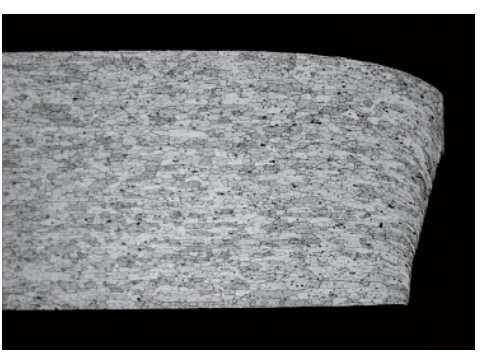

$15 \%$ clearance

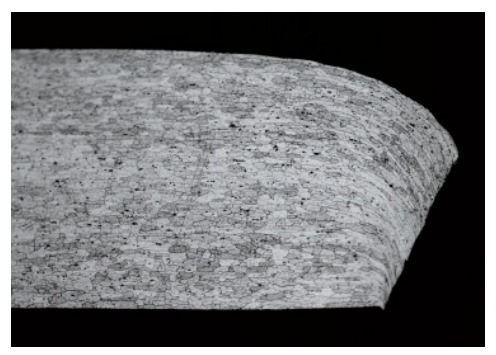

$40 \%$ clearance

(b) 


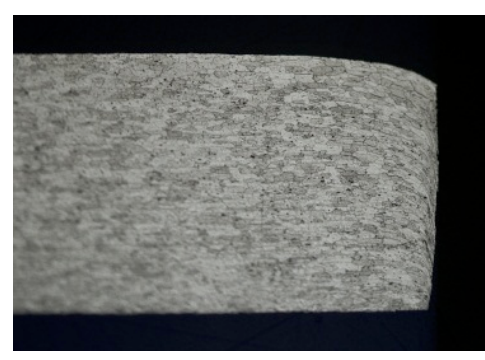

$5 \%$ clearance

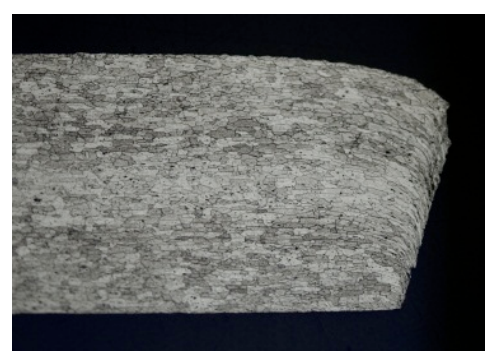

$20 \%$ clearance

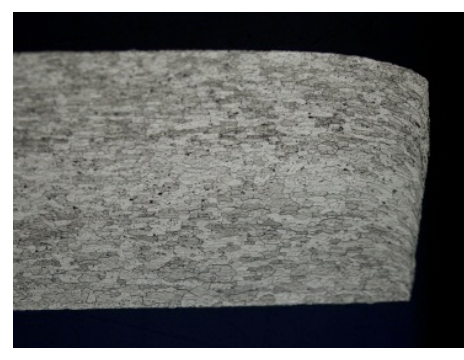

$10 \%$ clearance

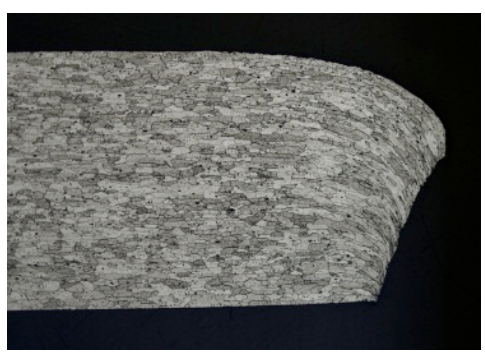

$30 \%$ clearance

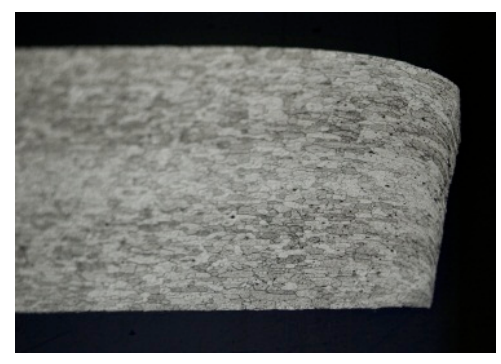

$15 \%$ clearance

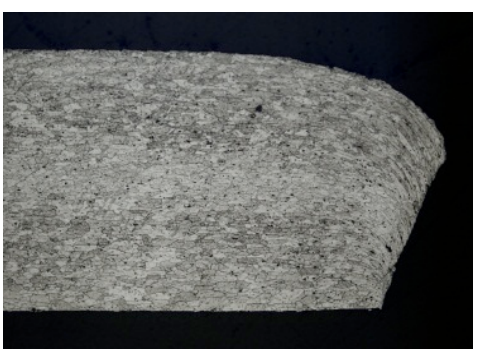

$40 \%$ clearance

(c)

Figure. 20 Microstructure of cross section of $0.9 \mathrm{~mm}$ thick as-received 6111-T4 half dog-bone sample trimmed with scrap support in (a) LD, (b) TD and (c) DD.

\section{Mechanism of fracture during stretchability study of samples trimmed with scrap support.}

Based upon the results of total elongations in the study of sheared edge stretchability, the average total elongation of half dog-bone samples trimmed with $40 \%$ clearance in LD is $19.7 \%$. In contrast, the average total elongation of TD and DD samples in the same clearance are $24.6 \%$ and $21.7 \%$ respectively. To investigate the potential reason which led to variation of total elongations between different rolling directions, the fracture mechanism of LD, TD and DD samples was analyzed by the methodology described in sections 4 and 5 for robust trimmed samples with $40 \%$ cutting clearance.

For all of the tested samples in LD, TD or DD directions, distinctly localized necking of the sheared surface started from the lower edge. It indicates that the lower edge of the sheared surface is vulnerable to local necking prior to fracture during stretching. For TD and DD directions, localized necking propagates from the lower edge to the upper edge of the sheared surface. 
For LD specimens, localized necking began at 15\% stretching (Fig.21 (a)). However, localized necking began at 25\% stretching for TD and DD specimens (Fig.21 (b) and Fig.21 (c)). It indicates that specimens with TD or DD rolling orientation have greater uniform plastic deformation than the specimens with LD rolling direction, which further led to prolonged total elongations of the sheared edge.

Significant localized necking was observed prior to major fracture for specimens in LD, TD and DD directions. For specimens in TD and DD directions, necking formed at sheared surface through the whole thickness. However, for LD specimens, localized necking initiated at the lower area of the sheared surface and led to fracture. For TD and DD specimens, failure occurred as a result of through thickness localized necking which occurred at a larger strain than for LD specimens.

From the major fracture pictures of samples in all three rolling directions, the propagation of major fracture as a split dominated for scrap support trimming conditions which resulted in failure mode 2 even though localized necking existed. These observations of fracture zones help to understand why the elongations of samples trimmed with scrap support and large cutting clearances are close to the results of stretching of samples trimmed with small cutting clearances.

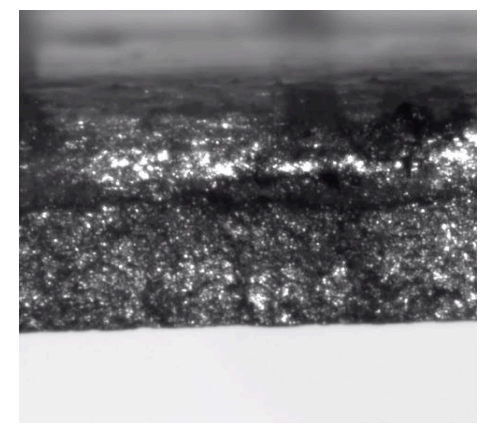

Initial

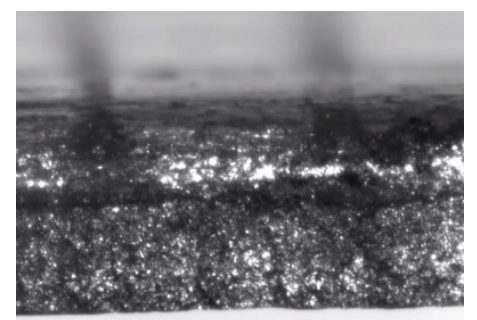

$5 \%$ stretching

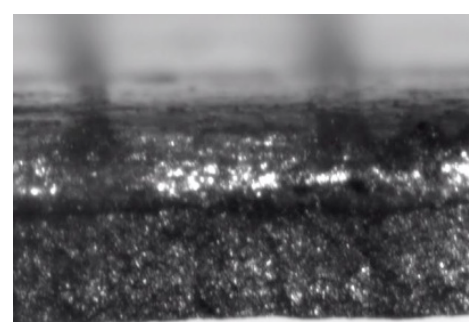

$10 \%$ stretching 


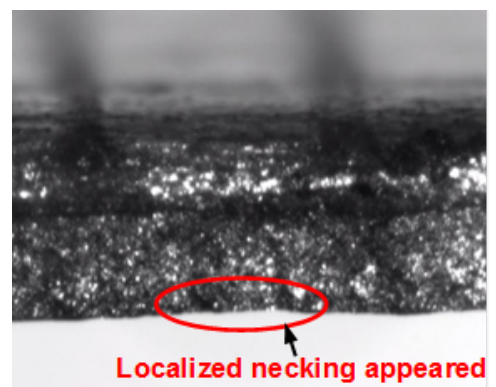

$15 \%$ stretching

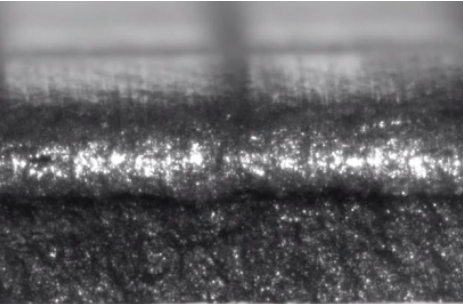

Initial

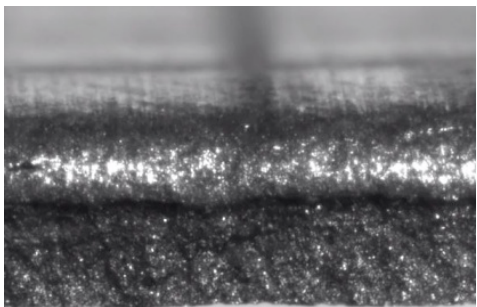

$15 \%$ stretching

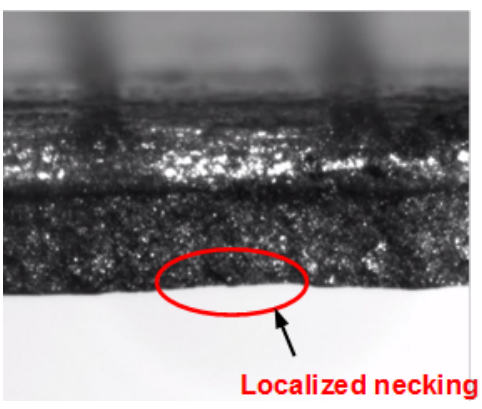

$20 \%$ stretching

(a)

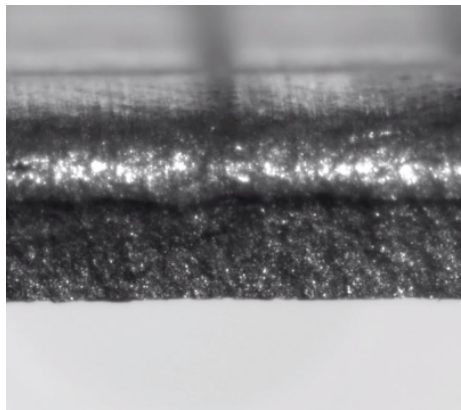

$5 \%$ stretching

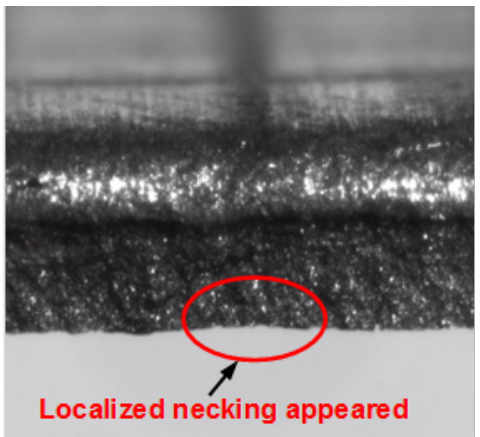

$20 \%$ stretching

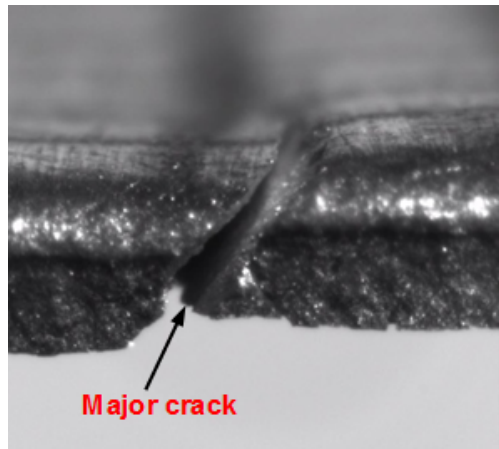

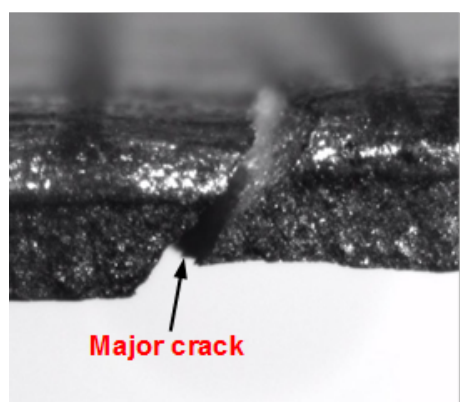

Almost fracture

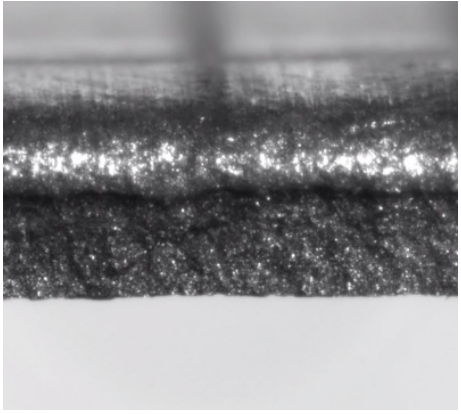

$10 \%$ stretching

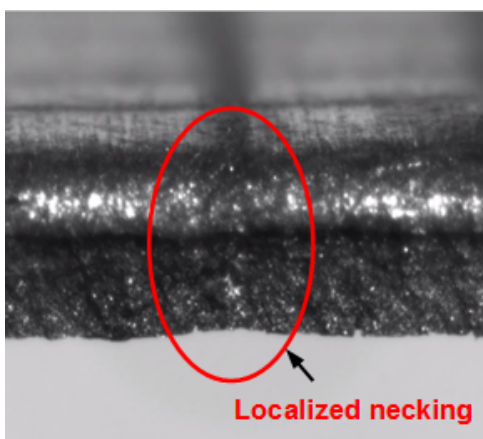

$25 \%$ stretching 
Almost fracture

(b)

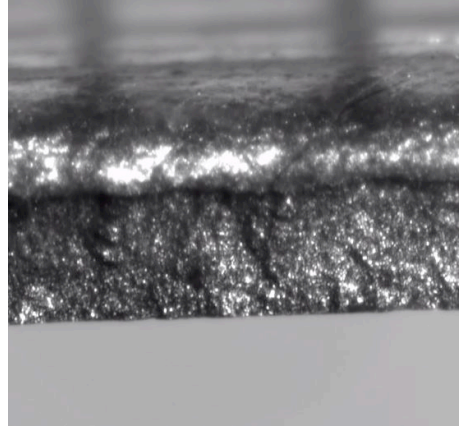

Initial

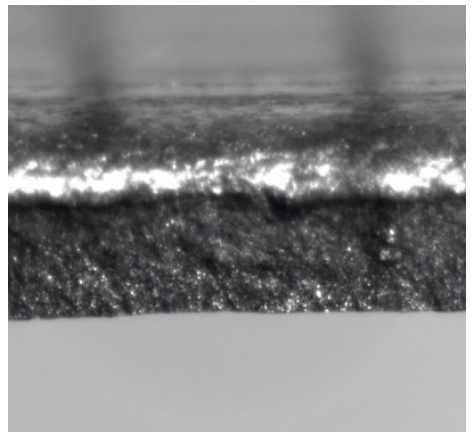

$15 \%$ stretching

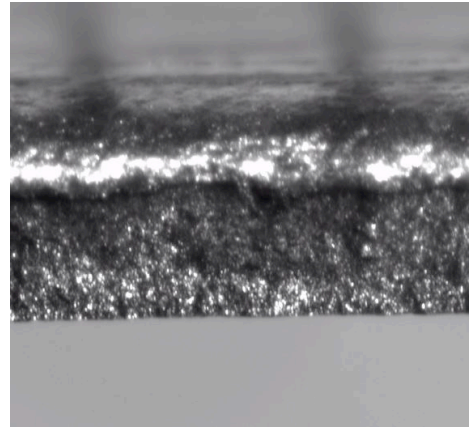

$5 \%$ stretching

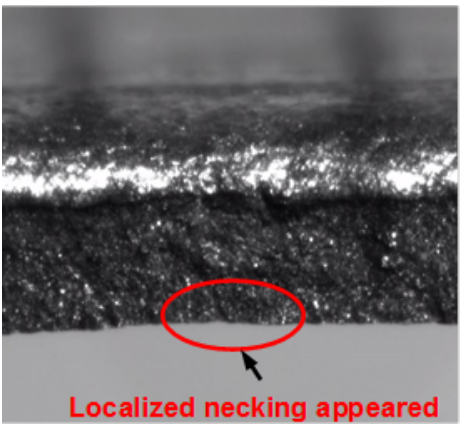

$20 \%$ stretching

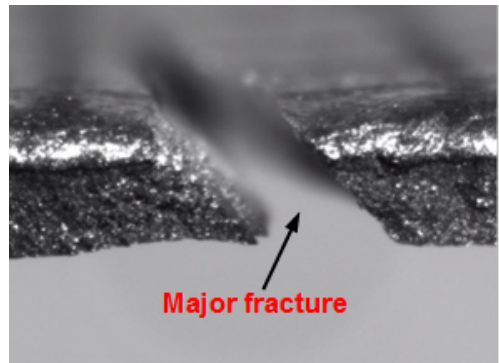

Almost fracture

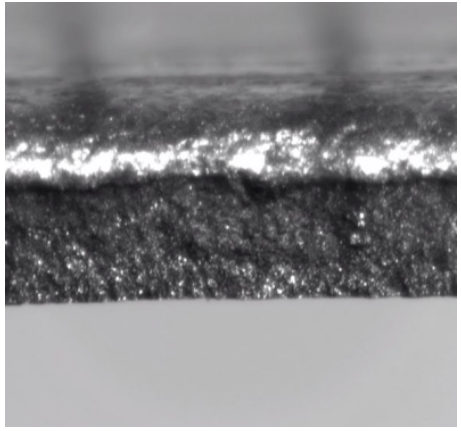

$10 \%$ stretching

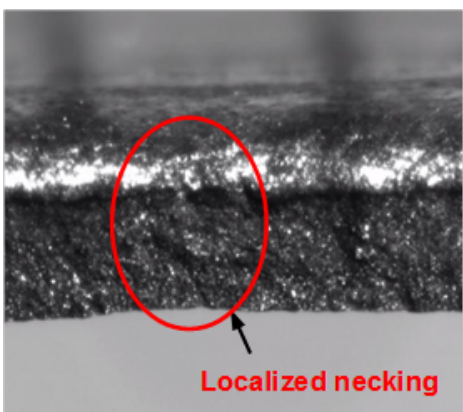

$25 \%$ stretching

(c)

Figure. 21 Localized necking prior to fracture of specimens in LD (a), TD (b) and DD (c).

\section{Potential reasons of fracture initiation during stretching of sheared edge produced by conventional and robust trimming.}


Performed experiments revealed two failure modes during tensile testing of half dog-bone samples with sheared edge. For conventional trimming with small clearances where no burr was formed, failure mode 1 was observed: the samples were fractured simultaneously through the whole width by forming a localized neck. For conventional trimming with larger clearances (10\% and above), fracture of samples was observed in failure mode 2: cracks propagate gradually through the width of the sample starting from the sheared edge. With increased cutting clearance, the burr width and height increased while the elongations of the sheared edge before fracture decreased.

For trimming process with scrap support, both failure modes were observed during stretching of half dog-bone samples. However, it should be admitted that the elongations of sheared edge are significantly less sensitive to clearance variations if this cutting process was employed. Below is an attempt to analyze the reasons of such behavior of the sheared edge.

As indicated in sections 5 and 8, during stretching of sheared samples, the fracture initiation in both failure modes was observed on the sheared surface from the tip of the burr or in the vicinity of the lower shearing edge. This behavior was common for all experiments even though the elongations of the sheared surface were substantially different and often dependent upon burr height. The clue to understanding this phenomenon is likely to be in the analysis of deformation conditions in this area. Such analysis was performed based on the experiments on partial shearing with various cutting parameters.

A typical case of fracture propagation and burr formation is illustrated in Fig. 22 , where conventional trimming was performed with $15 \%$ cutting clearance. In Fig. 22 (a), the cross-section of partially sheared sample is illustrated where shearing was performed almost to the point of fracture initiation. Some elongation of material was observed in the area of burr formation by comparing the grain aspect ratio in this area with such aspect ratio in the area of non-deformed material which was 3.6. In Fig. 22 (b), the cross-section of partially sheared sample is illustrated when the trimming process was stopped at the stage when all sheared edge was formed except the burr area. Comparing the grain aspect ratio of the burr area in Fig. 22 (a) and (b), which was 4.7 and 12.4 respectively, it was concluded that during final stage of the separation, the burr area is getting substantial 
additional deformation part of which occurs in the mode similar to plane strain tension. According to many studies on material ductility and damage under variable hydrostatic pressure, for example by Bai and Wierzbicki (2008), material elongations before fracture under plane strain tension are substantially lower than for the case of plan strain compression.

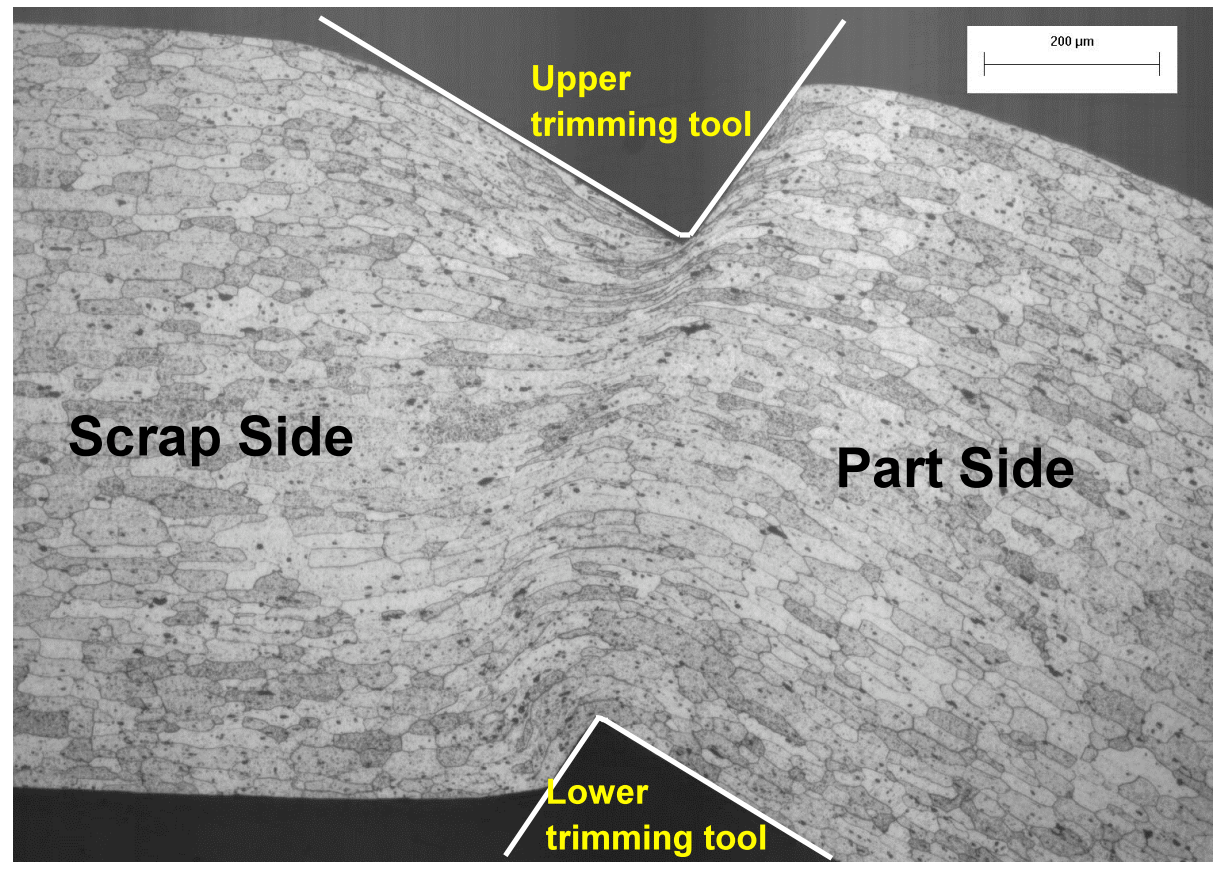

(a)

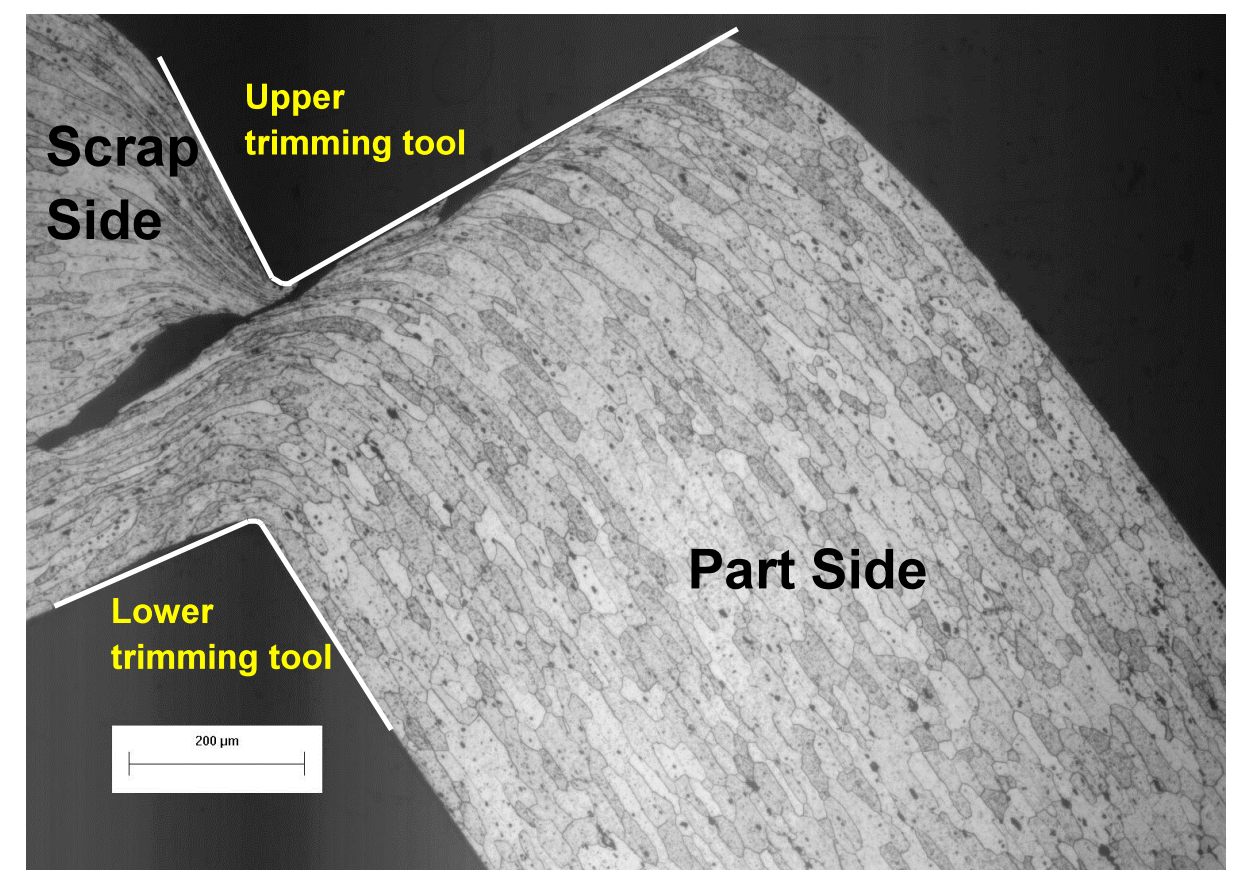


Fig. 22 Cross-sections of partially sheared samples conventionally trimmed with $15 \%$ cutting clearance: prior to initiation of fracture (a); during final stage of separation (b).

Therefore, this deformation mode brings substantially larger damage to the material in the burr area compared to the initial stage of indentation of the sharp sheared edges and formation of the burnished area where substantial hydrostatic pressure is present.

In case of trimming with rather small clearances, cracks often start from the vicinity of both upper and lower shearing edges from the point where material comes out of shearing edge and forms only very small burr typically proportional to the radius of the cutting edge. This fracture mechanism was illustrated by Golovashchenko (2008). In this case, the final stage of plane strain stretching of the burr did not occur and less damage was applied to the sheet metal.

When trimming process with scrap support was employed, fracture initiated from the lower shearing edge, as it is illustrated in Fig. 23, with some similarity to what was observed in the lower sheared edge area in case of trimming with very small cutting clearance and no plane strain stretching of the burr at the end of the process.

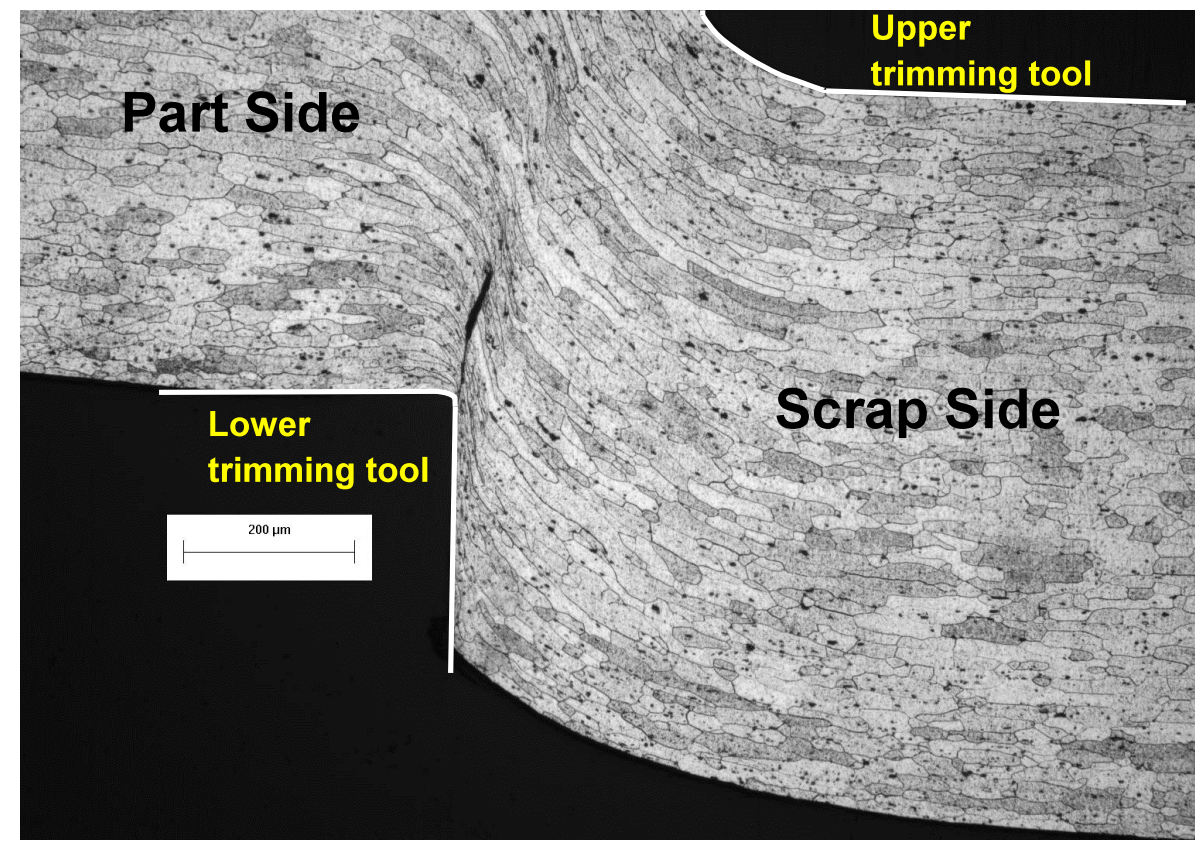


Fig. 23 Cross-section of a partially sheared sample using trimming process with scrap support in $20 \%$ cutting clearance.

Based on these observations, it becomes clear that if the sample is solution heat treated, the effect of work hardening is removed, and the burr does not represent a problem anymore. It also becomes clear that the stretchability of the sheared samples can be substantially improved if the burr is mechanically removed by deburring.

Performed experiments highlighted the importance of trimming with minimal burr height in the areas where stretching of sheared edge might take place, for example in stretch flanging and stretch hemming. This can be accomplished by controlling of the cutting clearance when possible and economically feasible. In cases where tight clearance is difficult to accomplish, for example in case of cam trimming in the corners of automotive panels where stiffness of the trim die might be insufficient to control the actual cutting clearance, technology of trimming process with scrap support can be employed. As illustrated above, this technology might be a viable solution to minimize the burr height for broad variation of clearances and have sufficient stretchability of the sheared edge.

Local heat treatment of already trimmed panels is another measure which can resolve the edge splitting issue if the stamping rate allows to implement it. Examples where such local heat treatment can be used are described by Krajewski (2006). Such a heat treatment procedure can be also employed if splitting occurred in assembly operation, for example in stretch hemming. In this case the postforming local heat treatment may be able to resolve the insufficient sheared edge stretchability.

Mechanical local deburring is another measure which can be utilized; however, this measure is rather labor intensive and probably could be employed only as a short term solution to save already stamped panels from splitting in assembly operations.

\section{Conclusions}

1. Investigation of the fracture mechanism of aluminum AA6111-T4 samples demonstrated that early fracture during stretching of the sheared edge originates from the burr tip and propagates perpendicular to the sheared surface. 
Multiple small cracks originate from the tip of the burr indicating that there is no single local defect which leads to reduced material elongation of sheared surface.

2. During the tensile tests of the samples trimmed with the clearance of approximately $5 \%$, localized necking followed by fracture similar to a standard tensile test was observed. No cracking was observed from the sheared surface prior to through thickness localization of deformation.

3. Deburring of samples trimmed with excessive clearance eliminated the effect of early fracture and provided stretchability similar to the case of trimming with accurate alignment of the tools.

4. Solution heat treatment of trimmed samples with fairly large burrs eliminated the effect of reduced stretchability.

5. Elimination of burrs using trimming process with scrap support also leads to substantial improvement in stretchability of the sheared edge in a broad range of cutting clearances.

\section{Acknowledgement}

This work was partially funded by the Department of Energy's Office of Vehicle Technologies under the Automotive Lightweighting Materials Program. Authors would like to acknowledge Dr. John Bonnen for useful discussions of heat treatment regimes.

\section{References}

ASTM Standard E8/E8M, 2008. Standard test methods for tension testing of metallic materials. ASTM International, vol. 03.01.pp. 66.

Bai, Y., Wierzbicki, T., 2008. A new model of metal plasticity and fracture with pressure and Lode dependence. International Journal of Plasticity, 24, pp. 1071-1096.

Butcher, C., Anderson, D., Worswick, J.M., 2013. Predicting failure during sheared edge stretching using a damagebased model for the shear affected zone. SAE Paper 2013-01-1166.

Chintamani, J., Sriram, S., 2006. Sheared edge characterization of steel products used for closure panel applications. SAE Paper 2006-01-1589.

Chiriac, C., 2010. A study of the plastic deformation of sheared edges of dual phase 780 steel. SAE Paper 2010-010441.

Golovashchenko, S.F., 1999. A study of trimming of Al alloy parts. Advanced Technology of Plasticity III, 22612266. 
Golovashchenko, S.F., 1999. Numerical and experimental analysis of the trimming process. Numisheet 99, 13-17.

Golovashchenko, S. F., 2006. A study on trimming of aluminum autobody sheet and development of a new robust process eliminating burrs and slivers. International Journal of Mechanical Sciences, 1384-1400.

Golovashchenko, S.F., 2008. Quality of trimming and its effect on stretch flanging of automotive panels. Journal of Materials Engineering and Performance, 17, pp. 316-325.

Golovashchenko, S.F., Ilinich M.A., 2005. Trimming of Advanced High Strength Steels. 2005 ASME International Mechanical Engineering Congress.

Hatch, E. J., 1984. Aluminum: Properties and physical metallurgy. American Society for Metals, Ohio.

Hecker, S.S., 1975. Simple technique for determining forming limit curves. Sheet metal industries, November 1975. pp. 671-673

International Standard ISO16630, 2009. Metallic materials - Sheet and strip - Hole expanding test., pp.1-7.

Johnson, W., Slater, R.A.C., 1967. Further experiments in quasi-static and dynamic blanking of circular discs from various materials. The Institution of Mechanical Engineers 180, 163-181.

Konieczny, A., Henderson, T., 2007. On formability limitations in stamping involving sheared edge stretching. SAE Paper 2007-01-0340.

Krajewski, E.P., 2006. The effect of retrogression heat treatments on aluminum flanging and trimming, SAE Paper 2006-01-0984.

Le, B. Q., deVries, A. James., Golovashchenko, S.F., Bonnen, J.F. John., 2013. Analysis of sheared edge formability of aluminum. Journal of Material Processing Technology, vol. 214, pp. 876-891.

Li, M., 2000. An experimental investigation on cut surface and burr in trimming aluminum autobody sheet. Int. J. Mech. Sci. 42, 889-906.

Pathak, N., Butcher, C., Worswick, J.M., Bellhouse, E., Gao, J., 2014. Edge formability and material characterization of hot-rolled multiphase steels. SAE Paper 2014-01-0992.

Seo, Y., 2005. Blanking questions have you on the edge? Understanding blanked edge characteristics improves stamping. The Fabricator. October 2005.

Stanton, M., Bhattacharya, R., Dargue, I., Aylmore, R., Williams, G., 2011. Hole expansion of aluminum alloys for the automotive industry. In: AIP Conference Proceedings.

Taupin, E., Breitling, J., Wu, W.-T., Altan, T., 1996. Material fracture and burr formation in blanking results of FEM simulations and comparison with experiments. Journal of Materials Processing Technology 59, 68-78.

Thipprakmas, S., Rojanananb, S., Paramaputic, P., 2008. An investigation of step taper-shaped punch in piercing process using finite element method. Journal of Materials Processing Technology 197, 132-139. 